\title{
Article \\ The MarR-Type Regulator PA3458 Is Involved in Osmoadaptation Control in Pseudomonas aeruginosa
}

\author{
Karolina Kotecka (D), Adam Kawalek (D), Kamil Kobylecki (D) and Aneta Agnieszka Bartosik *(D) \\ Institute of Biochemistry and Biophysics, Polish Academy of Sciences, 02-106 Warsaw, Poland; \\ ka.kotecka@ibb.waw.pl (K.K.); a.kawalek@ibb.waw.pl (A.K.); kkobylecki@ibb.waw.pl (K.K.) \\ * Correspondence: anetab2@ibb.waw.pl; Tel.: +48-225921-215
}

Citation: Kotecka, K.; Kawalek, A. Kobylecki, K.; Bartosik, A.A. The MarR-Type Regulator PA3458 Is Involved in Osmoadaptation Control in Pseudomonas aeruginosa. Int. J. Mol. Sci. 2021, 22, 3982. https://doi.org/ $10.3390 /$ ijms 22083982

Academic Editor: Alexey A. Malygin

Received: 3 March 2021

Accepted: 9 April 2021

Published: 12 April 2021

Publisher's Note: MDPI stays neutral with regard to jurisdictional claims in published maps and institutional affiliations.

Copyright: (c) 2021 by the authors. Licensee MDPI, Basel, Switzerland. This article is an open access article distributed under the terms and conditions of the Creative Commons Attribution (CC BY) license (https:// creativecommons.org/licenses/by/ $4.0 /)$.

\begin{abstract}
Pseudomonas aeruginosa is a facultative human pathogen, causing acute and chronic infections that are especially dangerous for immunocompromised patients. The eradication of $P$. aeruginosa is difficult due to its intrinsic antibiotic resistance mechanisms, high adaptability, and genetic plasticity. The bacterium possesses multilevel regulatory systems engaging a huge repertoire of transcriptional regulators (TRs). Among these, the MarR family encompasses a number of proteins, mainly acting as repressors, which are involved in response to various environmental signals. In this work, we aimed to decipher the role of PA3458, a putative MarR-type TR from P. aeruginosa. Transcriptional profiling of $P$. aeruginosa PAO1161 overexpressing PA3458 showed changes in the mRNA level of 133 genes; among them, 100 were down-regulated, suggesting the repressor function of PA3458. Concomitantly, ChIP-seq analysis identified more than 300 PA3458 binding sites in $P$. aeruginosa. The PA3458 regulon encompasses genes involved in stress response, including the PA3459-PA3461 operon, which is divergent to PA3458. This operon encodes an asparagine synthase, a GNAT-family acetyltransferase, and a glutamyl aminopeptidase engaged in the production of $\mathrm{N}$-acetylglutaminylglutamine amide (NAGGN), which is a potent bacterial osmoprotectant. We showed that PA3458-mediated control of PA3459-PA3461 expression is required for the adaptation of $P$. aeruginosa growth in high osmolarity. Overall, our data indicate that PA3458 plays a role in osmoadaptation control in P. aeruginosa.
\end{abstract}

Keywords: Pseudomonas aeruginosa; PA3458; MarR-type transcriptional regulator; repressor; osmoadaptation

\section{Introduction}

P. aeruginosa is a common bacterium that survives in variable environmental conditions, including the human body, and it is the main agent causing nosocomial infections of the lungs, wounds, blood, and urinary tracts [1]. P. aeruginosa is the leading cause of mortality in cystic fibrosis patients [2]. Treatment of the acute and chronic infections caused by this bacterium is very difficult due to its adaptability and intrinsic antibiotic resistance mechanisms [3]. P. aeruginosa has complex regulatory systems, which allow it to combat environmental stressors with the use of different mechanisms; e.g., in the presence of an antibiotic, cells could use efflux pumps [4] or form biofilm [5]. The multilevel regulatory network allows P. aeruginosa to modulate the metabolism to endure different stress conditions e.g., heat shock [6], the presence of antimicrobials [7], photooxidative [8], or osmotic stress $[9,10]$.

Quick and adequate responses of P. aeruginosa to different environmental signals are possible due to complex regulatory systems, which engage more than 500 characterized or potential transcriptional regulators and two-component regulatory system proteins [11], comprising almost $10 \%$ of all its genes. Nineteen prokaryotic transcriptional regulator families have been evaluated so far [12], including the MarR family of transcriptional regulators. 
Acting mainly as repressors, MarR-type TRs are involved in the control of different processes e.g., adhesion, virulence, and antibiotic resistance [13]. The first and the beststudied regulator from this family is the multiple antibiotic resistance regulator MarR from Escherichia coli [14]. It was originally identified as a component encoded within the E. coli marR $A B$ locus, which negatively regulated the expression of this operon [15]. The MarR works as a dimer, and the $\mathrm{N}$-terminal part of the protein is important for protein oligomerisation. The C-terminal part of MarR contains the winged-helix-turn-helix (wHTH) motif, which is involved in DNA recognition and binding [14]. The MarR binding to DNA is inhibited by salicylate, forming a complex with MarR [16]. MarA acts as an autoactivator of $\operatorname{mar} R A B$ but is also involved in the regulation of multiple other genes affecting resistance to antibiotics and other environmental hazards [17,18].

Representatives of the MarR family often show similar organization of genetic loci with a regulator gene and usually divergently oriented target genes. The regulator controls the activity of its gene and a divergently oriented gene or operon by binding to the intergenic region and blocking RNA polymerase by steric inhibition [19].

A vast number of the described MarR-type TRs are involved in the control of virulence and stress response genes, e.g., HpaR of Xanthomonas campestris [20]; PrhN of Ralstonia solanacearum [21]; SlyA of Dickeya dadantii [22], Enterococcus faecalis [23,24], or Salmonella typhimurium [25]; YodB of Bacillus subtilis [26]; CosR in Corynebacterium glutamicum [27] or BmoR of Bacteroides fragilis [28].

In P. aeruginosa PAO1, thirteen genes coding for MarR-type regulators were identified based on NCBI [29] and pseudomonas.com [30] databases. The best-characterized known and important from the clinical point of view is MexR (PA0424), which negatively regulates multidrug efflux systems [31]. Mutation in the mexR gene causes higher resistance to antibiotics [32]. It was shown that the oxidation stress may serve as a signal to MexR, causing inhibition of binding to DNA [33]. Similarly, the P. aeruginosa ohrR (PA2849) and $\operatorname{ospR}(P A 2825)$ both encoded MarR-type regulators, which control hydroperoxide stress response [34]. Another MarR-type TR from P. aeruginosa, HudR (PA0253), acts as a repressor of the $h u d A$ gene encoding a virulence-attenuating factor [35].

The PA3458 protein from P. aeruginosa has been classified in silico as a putative MarRtype transcriptional regulator. The $P A 3458$ gene is part of the $\operatorname{par} A /$ par $B$ regulatory network (it is up-regulated in P. aeruginosa parA and parB mutants) [36]. There are more than 690 and 1160 genes in ParA and ParB regulon, respectively. ParA and ParB are involved in chromosome segregation, which is manifested by anucleate cell formation and slight cessation of mutants growth $[37,38]$, but genes in their regulon represented different functional categories, among them a huge amount of genes encoding transcriptional regulators [36]. Their role in P. aeruginosa biology and metabolism in many cases awaits elucidation.

The aim of this study was identification of the function of the MarR-family transcriptional regulator PA3458 in P. aeruginosa.

\section{Results}

\subsection{The PA3458-PA3461 Gene Cluster of P. aeruginosa}

The PA3458 gene in P. aeruginosa PAO1161, similarly to PAO1, is encoded in the opposite transcriptional orientation to the predicted PA3459-PA3461 operon (Figure 1A), which according to the pseudomonas.com database encodes an asparagine synthase (PA3459), a GNAT-family acetyltransferase (PA3460), and a glutamyl aminopeptidase (PA3461). Comparative microarray analysis showed that the PA3459-PA3461 genes were up-regulated in P. aeruginosa cells in response to osmotic stress [9]. They encode proteins involved in the production of an $\mathrm{N}$-acetylglutaminylglutamine amide (NAGGN), a potent osmoprotectant conferring bacterial cells with resistance to osmotic stress [9]. The close genomic localization of the PA3458 gene to the PA3459-PA3461 gene cluster suggests a functional relationship. 
A
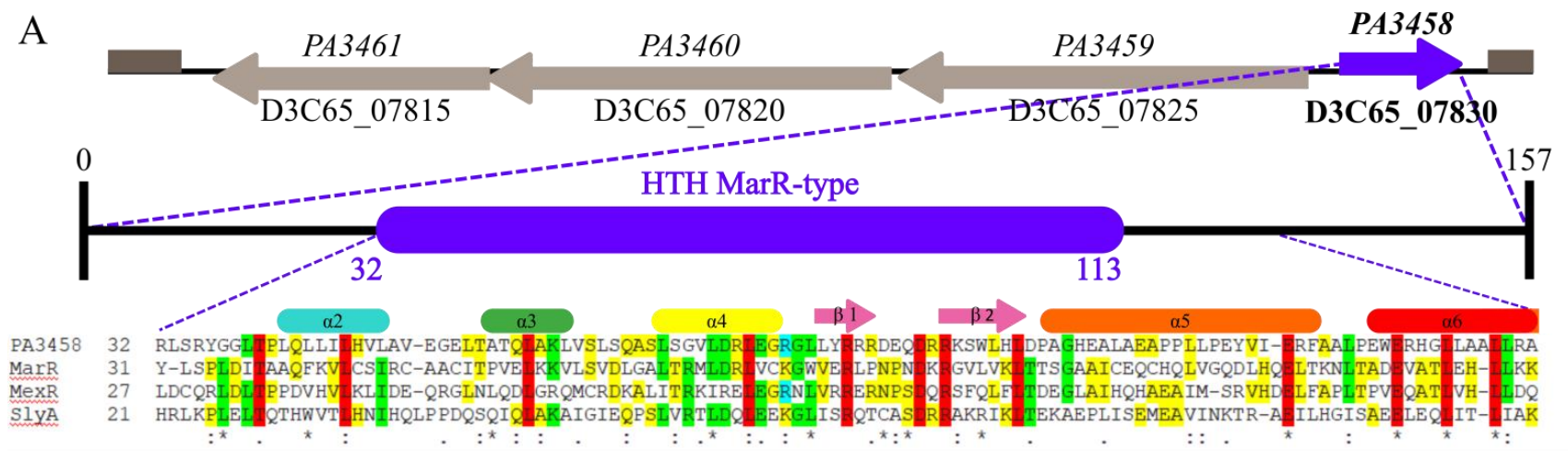

B

$\mathrm{C}_{\mathrm{MW}}$ Glutaraldehyde [\%] Glutaraldehyde [\%] $\mathrm{D}$
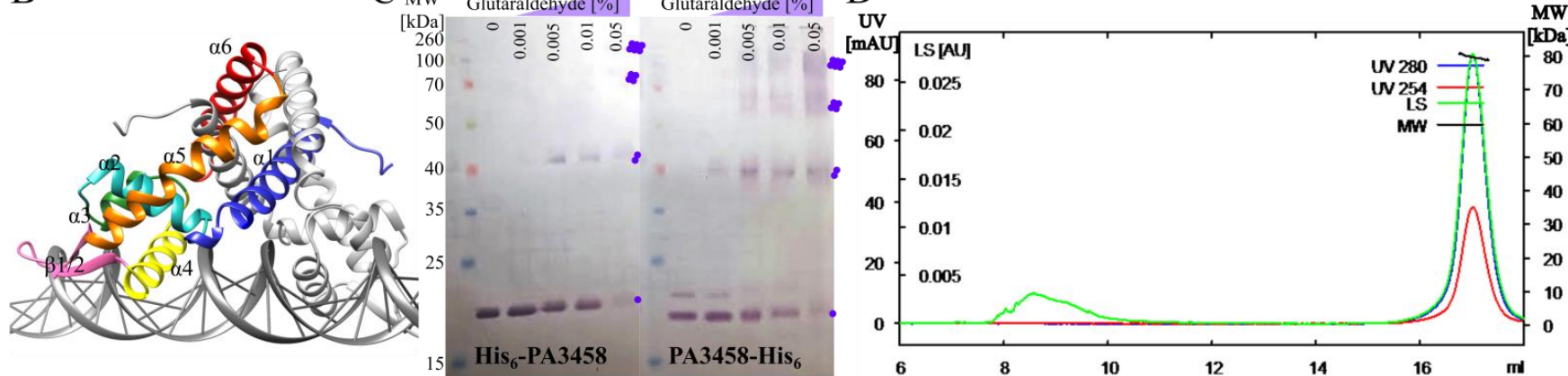

Figure 1. Characterization of PA3458 protein from P. aeruginosa. (A) Genomic context of the PA3458 gene in the PAO1161 genome and the domain structure of the PA3458 protein. The gene IDs from PAO1 and PAO1161 strains are presented. Alignment represents comparison of PA3458 with corresponding regions of MarR (GenBank: AAK21292.1), MexR (GenBank: AVV61365.1), and SlyA (GenBank: AAL55673.1). Sequences were aligned using the Clustal Omega [39] with identical residues in all proteins marked with red, in three sequences with green or in two with yellow, respectively. The secondary structure elements are marked with colored boxes corresponding to predicted domains presented in (B). (B) Structural model of PA3458 dimer bound with DNA. The model was built using SWISS-MODEL and HDOCK [40,41]. (C) Oligomerization state of purified $\mathrm{His}_{6}$-PA3458 and PA3458-His 6 assayed by crosslinking of purified protein with glutaraldehyde. Samples were separated using SDS-PAGE and immunodetected with anty-His antibodies. A violet dot indicates a monomer, two dots indicate a dimer, four indicate tetramers, and six indicate hexamers. (D) Size exclusion chromatography (SEC) with multi-angle static light scattering (MALS) analysis for PA3458-His 6 . Left axis-UV and light scattering (LS) absorption, right axis-molecular weight of protein (MW).

The PA3458 gene encodes a protein classified in silico as a potential MarR-type transcriptional regulator. It encodes a small protein of 157 residues $(17.6 \mathrm{kDa})$, with a predicted winged helix-turn-helix (wHTH) domain responsible for DNA binding. Upon comparison of the part of the protein encompassing the wHTH motif with DNA binding domains of MarR-type representatives, MarR from E. coli [42], MexR from P. aeruginosa [31], and SlyA from Enterobacteriaceae [43] showed the presence of highly conserved residues potentially engaged in DNA binding (Figure 1A). Secondary structure prediction using SWISS-MODEL and HDOCK servers [40,41] predicted a dimer of a triangular shape formed by two PA3458 monomers, each consisting of six $\alpha$-helices and two $\beta$-strands arranged in the order $\alpha 1$ $\alpha 2-\alpha 3-\alpha 4-\beta 1-\beta 2-\alpha 5-\alpha 6$ in the primary structure (Figure $1 \mathrm{~A}, \mathrm{~B})$. The dimerization interface is formed by helices $\alpha 1, \alpha 5$, and $\alpha 6$ of two monomers, while helices $\alpha 3$ and $\alpha 4$ form a helix-turn-helix (HTH) involved in DNA binding. Between helices $\alpha 4$ and $\alpha 5$ is a wing motif comprising two antiparallel $\beta$-strands and their connecting loop. The wHTH with $\alpha$-helix $4(\alpha 4)$ is critical for interactions with DNA (Figure 1B). The predicted structure of PA3458 resembles the structures of other MarR family proteins [44,45].

To check the oligomeric state of PA3458, two methods were used. Glutaraldehyde crosslinking of purified $\mathrm{His}_{6}$-PA3458 and PA3458-His ${ }_{6}$, followed by Western blot analysis, showed the presence of dimmers as well as higher-order complexes corresponding in size to tetramers (Figure 1C). In the case of PA3458-His 6 fusion, the oligomers were crosslinked 
more efficiently, which suggests that the free $\mathrm{N}$-terminus of the protein may be required for PA3458 self-assembly. Similarly, analysis of the oligomeric state of PA3458-His 6 using SEC-MALS demonstrated that this protein existed preferentially as a tetramer in solution under the tested conditions (Figure 1D). These data indicates that PA3458 is able to selfassemble and creates oligomers. The oligomeric state of the protein may play an important regulatory role in protein action as the transcriptional regulator.

\subsection{Effect of PA3458 Lack or Excess on Bacterial Growth}

To assign a biological function to PA3458, the chromosomal mutant of PAO1161 $\triangle P A 3458$ was constructed using the allele exchange method (Tables A1 and A2). The phenotype analysis of the $\triangle P A 3458$ mutant in comparison with WT did not show significant changes in bacterial growth, motility abilities, or biofilm formation under tested conditions (Figure A1).

To further determine the influence of PA3458 on bacterial growth, the PA3458 gene was cloned under the control of araC-BADp in the broad host range expression vector $\mathrm{pKGB8}$, which is the derivative of pBBR1-MCS1 [46,47]. The growth of E. coli DH5 $\alpha$ (pKKB2.11 araBADp-PA3458) and DH5 $\alpha$ (pKGB8 araBADp) cells conducted under selection in LuriaBertani (LB) broth in the presence of different concentrations $(0-0.2 \%)$ of inducer arabinose was tested. Irrespective of the PA3458 overexpression or its lack, no difference in the kinetics of bacterial growth was detected under tested conditions (Figure 2A).
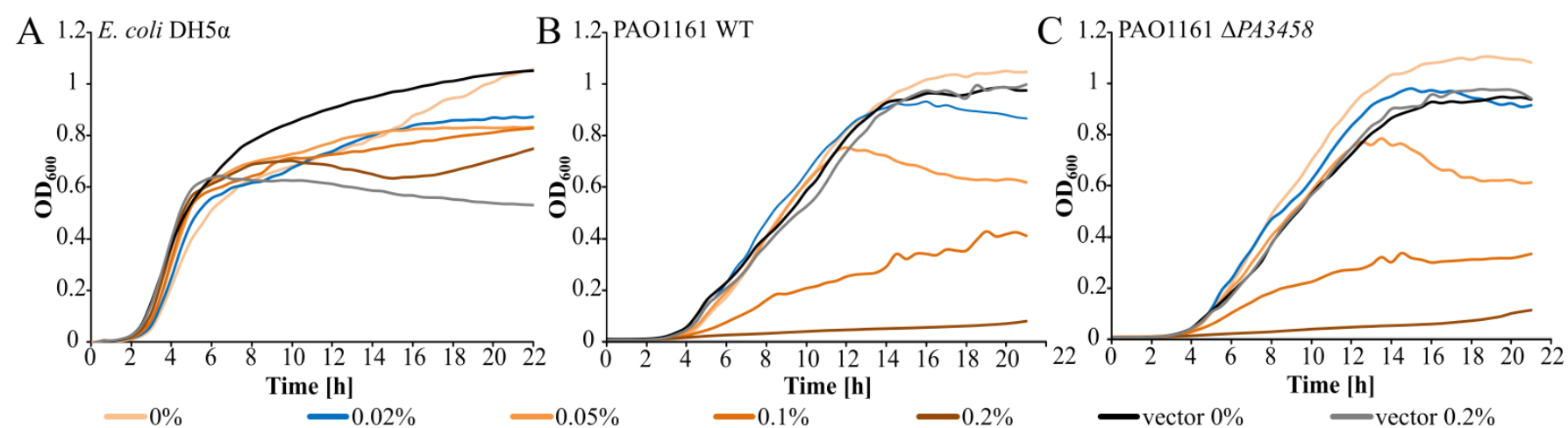

Figure 2. Effect of PA3458 excess on bacterial growth. E. coli DH5 $\alpha$ (A) or P. aeruginosa PAO1161 (B) or $\triangle P A 3458$ (C) mutant strains carrying empty vector pKGB8 araBADp or pKKB2.11 araBADp-PA3458 were grown in Luria-Bertani (LB) broth under selection with the indicated concentration of inducer arabinose ( 0 to $0.2 \%)$. The blue line indicates the growth in the presence of $0.02 \%$ arabinose, conditions selected for RNA-seq analysis. Data represent mean optical density at $600 \mathrm{~nm}$ $\left(\mathrm{OD}_{600}\right)$ from three independent replicates. Standard deviations are less than $20 \%$ and are not shown for clarity.

The growth of P. aeruginosa PAO1161 and PAO1161 $\triangle P A 3458$ mutant with pKKB2.11 $\operatorname{araBADp}-P A 3458$ or empty vector (pKGB8 araBADp) in the presence of different concentrations of arabinose was also tested. The slight PA3458 overproduction in the presence of $0.01-0.05 \%$ arabinose did not affect the bacterial growth visibly (Figure $2 B, C$ ). Induction of the PA3458 expression by the addition of the higher concentrations of arabinose $(0.1-0.2 \%)$ to the cultures affected significantly kinetics of bacterial growth, with the strongest slow down effect observed for the highest arabinose concentration tested $(0.2 \%)$. An addition of arabinose did not affect the growth of cells carrying the empty vector.

These data show that the higher level of PA3458 in the cells has a strong negative impact on the growth of $P$. aeruginosa but not of E. coli, suggesting the existence of the sensitive targets of PA3458 action in P. aeruginosa cells.

\subsection{Effect of Increased PA3458 Level on Gene Expression}

To identify the potential functions and pathways associated with the action of PA3458 in P. aeruginosa, we set out to determine its regulon. The impact of slight PA3458 overproduction on gene expression was analyzed using RNA-seq analysis, and concomi- 
tantly, PA3458 binding sites in the P. aeruginosa genome were identified using chromatin immunoprecipitation-sequencing (ChIP-seq). RNA was isolated from logarithmically growing $\left(\mathrm{OD}_{600}\right.$ 0.5) PAO1161 (pKKB2.11 arapBAD-PA3458) cells grown under selection in LB with $0.02 \%$ arabinose representing conditions of the slight PA3458 overproduction, not perturbing bacterial growth (hereafter called PA3458+) and PAO1161 (pKGB8 araBADp) cultures grown under selection in LB with $0.02 \%$ arabinose (empty vector control, hereafter called EV+). We used the low concentration of arabinose $(0.02 \%)$ to induce the PA3458 production and not affect the cell growth, which is observed when higher concentrations of arabinose are used, leading to high PA3458 overproduction and strong inhibition of bacterial growth (Figure 2B).

Comparative transcriptome analysis of PA3458+ vs. EV+ cells indicated 133 loci with an altered expression in response to the excess of PA3458 in the PAO1161 cells (fold change $(\mathrm{FC}) \leq-2$ or $\geq 2$, false discovery rate (FDR) adjusted $p$-value $\leq 0.01$ ) (Figure $3 \mathrm{~A}$; Table S1). Among identified loci, 33 exhibited increased mRNA levels and 100 showed decreased mRNA levels. Genes with altered expression mostly belong to the transport of small molecules and amino acid metabolism PseudoCAP categories [30], 23 and 20 genes, respectively. Interestingly, most of these genes were down-regulated. The category with the highest enrichment (14\%) encompasses eight genes (seven down-regulated) encoding chaperones and heat shock proteins (Figure 3A). Almost all genes assigned to class I, encompassing genes with adaptation, protection, and motility functions were also downregulated. Additionally, the down-regulated genes encompass all, except one, representatives encoding functions connected with cellular processes (class IV), as well as many genes assigned to class II and V; thus, they are engaged in membrane functions and metabolism (Figure 3A).

The volcano plot highlighted genes with the most significant changes (Figure 3B). For selected genes, RT-qPCR verification of changes observed in RNA-seq analysis was performed (Figure 3C). Importantly, for all tested genes, the direction of changes is consistent for both analyses.

\subsection{Identification of PA3458 Binding Sites in P. aeruginosa}

To identify the PA3458 binding sites in the PAO1161 genome, the ChIP-seq analysis was conducted using the PAO1161 $\triangle P A 3458$ strain carrying pKKB2.12 (araBADp-PA3458flag) and anti-FLAG antibodies. The PA3458-FLAG fusion protein, when overproduced, exhibited a similar effect on P. aeruginosa growth as the untagged PA3458 (Figure A2), confirming the functionality of the fusion protein. The ChIP-seq analysis was performed on DNA isolated from PAO1161 $\triangle P A 3458$ (pKKB2.12 araBADp-PA3458-flag) cells grown with $0.02 \%$ arabinose, conditions of the slight protein overproduction not perturbing bacterial growth (hereafter called PA3458-F+) and PAO1161 $\triangle P A 3458$ (pABB28.3 araBADp-flag) control cultures grown in the same conditions (hereafter called EV-F). The anti-FLAG immunoprecipitated DNA from three biological samples of PA3458-F+ and one EV-F was sequenced, and the reads were mapped to the P. aeruginosa PAO1161 genome [48]. To identify the sequences corresponding to the PA3458 binding sites, peak calling on merged data for three replicates was performed, as justified by the high similarity of coverage data between replicates (data not shown). Data obtained for EV-F sample were used to eliminate the regions enriched non-specifically during the ChIP procedure with the antibodies. Using the FDR-adjusted $p$-value cut-off value of 0.05 and fold enrichment $(\mathrm{FE})>1.5,1183 \mathrm{ChIP}$ seq peaks were identified (Figure 4A; Table S2). The peaks displayed FE up to 31.28, with a median of 7.0. We have noted that the fold enrichment for peaks with intergenic summits was generally higher than for those that were located in gene bodies (Figure 4A). To decrease the number of non-specific binding sites, further analyses were limited to 319 peaks with FE $>5$ (Table S3). Summits of 164 peaks from 319 mapped to intergenic regions (Figure 4A). A global analysis of functional categories of the genes ascribed to the PA3458-binding regions identified the transport of small molecules, membrane proteins, and transcriptional regulators as the most represented categories (Figure 4B). 

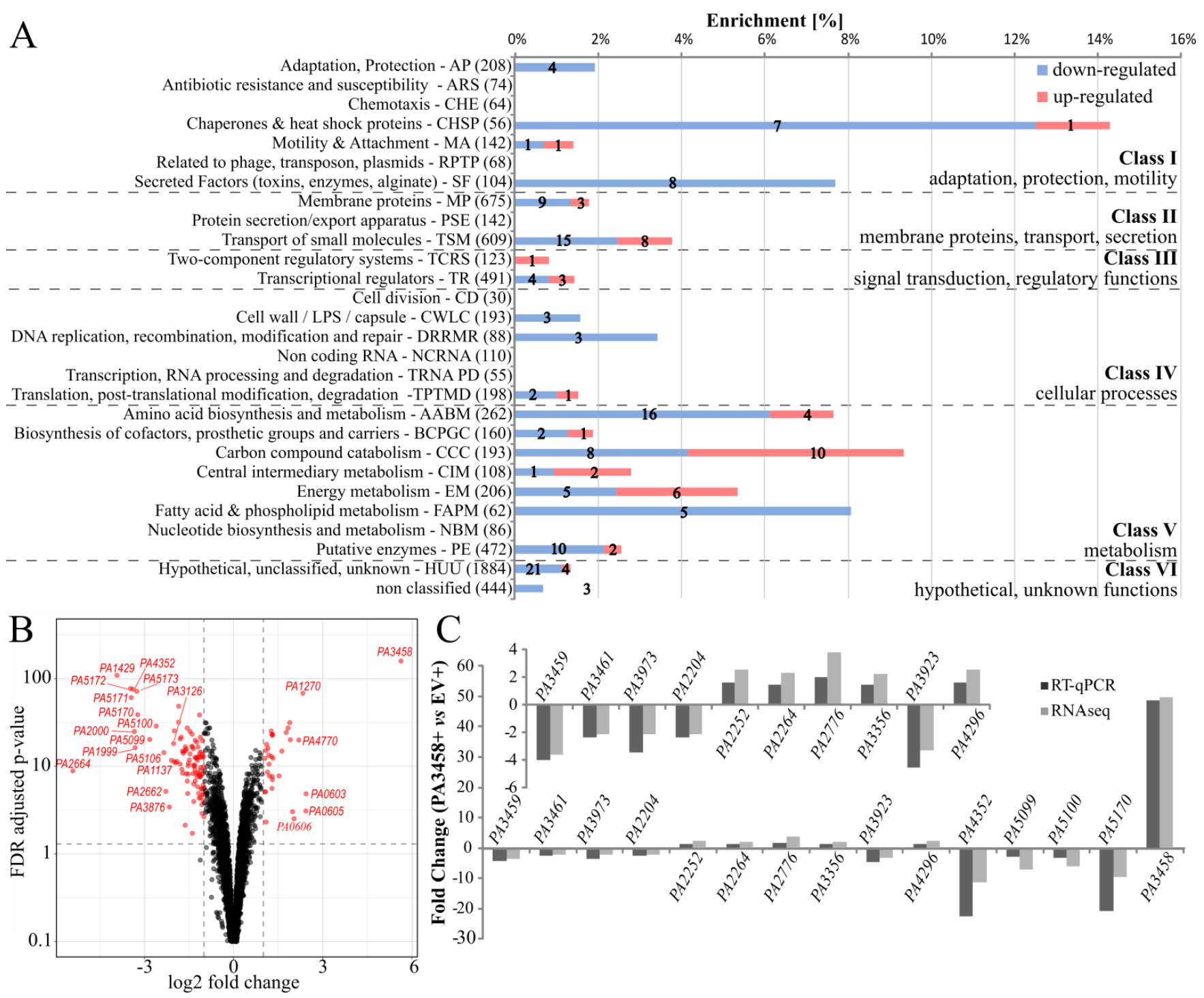

Figure 3. Identification of P. aeruginosa genes affected by PA3458. Comparative transcriptome analysis was performed for PA3458 overproducing cells PA3458+ vs. EV+ P. aeruginosa PAO1161 cells. (A) Enrichment of PseudoCAP functional categories [30] for 133 genes showing changes in mRNA level in response to mild PA3458 abundance (FC $\leq-2$ or $\geq 2$, FDR adjusted $p$-value $\leq 0.01$ ). The numbers in brackets show the number of all genes in the PAO1 genome in the indicated PseudoCAP category. One gene could be classified into more than one category. Numbers in red or blue bars denote the number of up- or down-regulated genes, respectively, in each category. The PseudoCAP categories were grouped into six more general classes. (B) Volcano plot visualization of differential expression in analysis between transcriptomes of PA3458+ vs. EV+ cells. Each point in the volcano plot represents one gene, and the dashed lines represent the cut-off values used. The red dots represent the most significant changes. (C) Validation of RNA-seq data by RT-qPCR analysis. The RT-qPCR was performed using RNA samples obtained for the same conditions as samples used for RNA-seq analysis. Data represent mean fold change for three biological replicates. The pro $C$ was used as a reference gene.

Comparison of the ChIP-seq data with RNA-seq data (Figure 4C) pointed out four intragenic and 11 intergenic PA3458 binding sites in proximity of a gene with transcript level affected by PA3458 excess (Table 1). Of these, nine loci showed PA3458 bound sites upstream of genes regulated by PA3458 abundance, suggesting a direct involvement of PA3458 in their regulation (Figure 4D). Interestingly, they encode proteins potentially involved in stress response (PA2664, PA2665, PA1429, PA1270, PA4352, and PA3459) and amino acid metabolism (PA2264, PA5170, PA5100, and PA2015) (Table 1). 
A

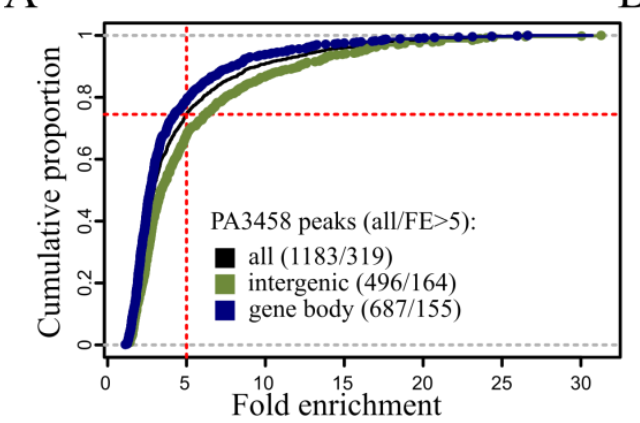

C

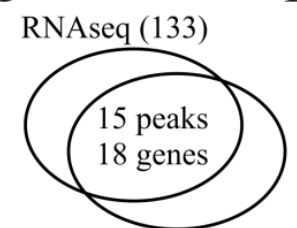

ChIPseq (319)

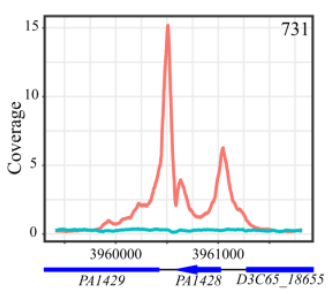

E

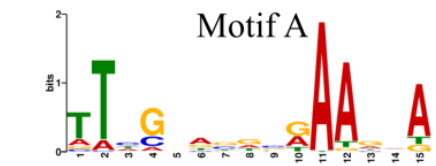

TTHGNASDSRAARDÁ

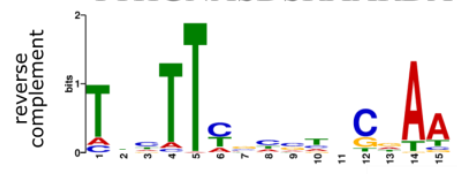

B

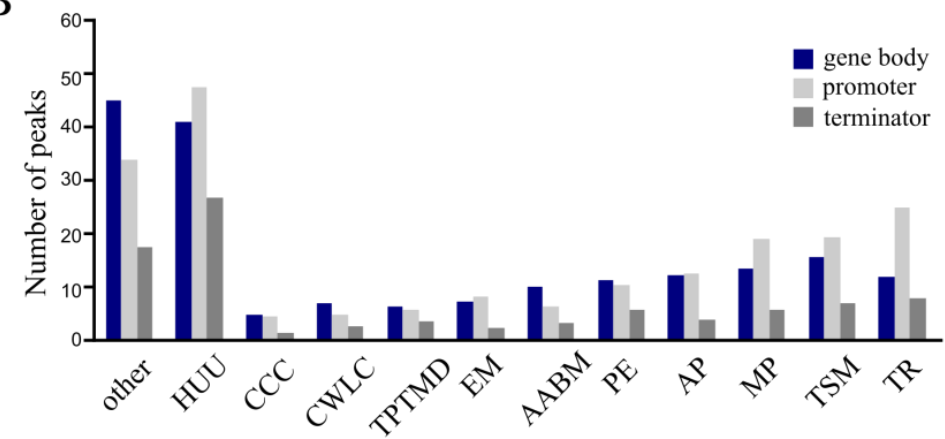

D
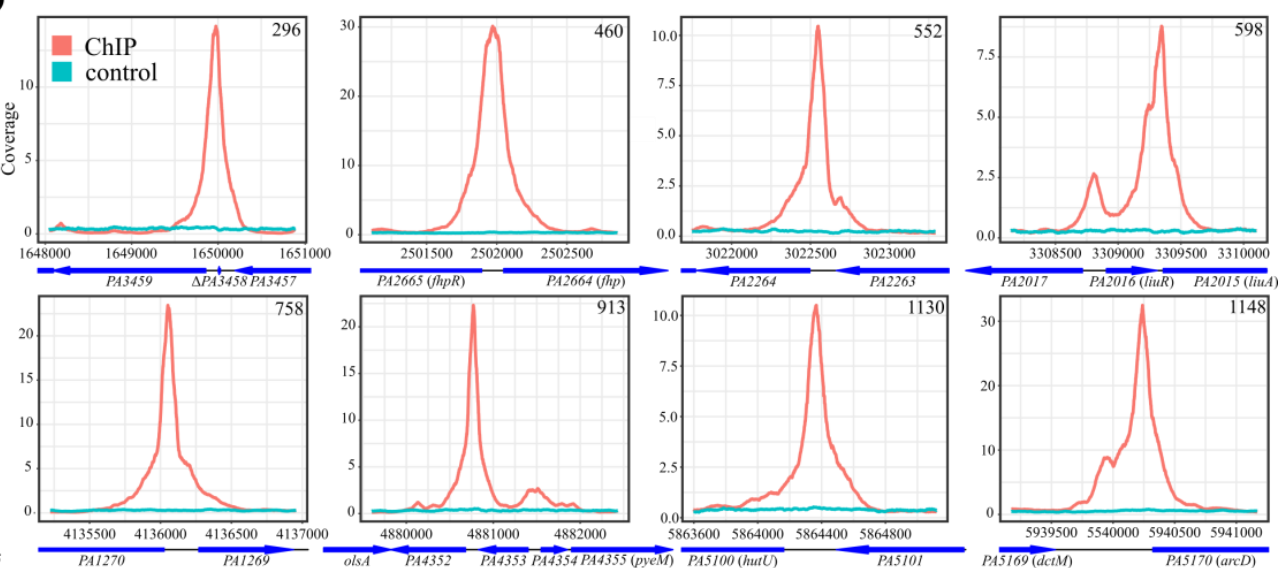

$\mathrm{F}$

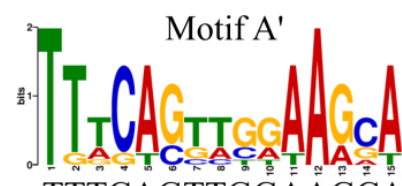
TTTCAGTTGGAAGCA

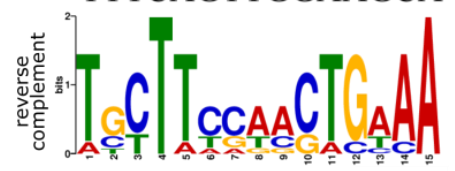

G

\begin{tabular}{|c|c|}
\hline \begin{tabular}{|l|}
$P A 3459$ \\
\end{tabular} & \multirow{2}{*}{ TTACA $G T T G \subset A A G \subseteq A$} \\
\hline PA3458 & \\
\hline 42664 & \multirow[b]{2}{*}{ TTTCACCTC $\subseteq A A \in C A$} \\
\hline \begin{tabular}{|l|} 
PA2665 \\
\end{tabular} & \\
\hline PA5170 & TTTCAGTAGCAAGCT \\
\hline PA2264 & $\mathrm{TGT}$ \\
\hline \begin{tabular}{|l|} 
PA1270 \\
\end{tabular} & TTAGCTTGC \\
\hline PA4352 & $C C \subset A A \subset C A$ \\
\hline PA1429 & \\
\hline PA2016 & \multirow[b]{2}{*}{ TTACA $G \in T \in A A A G C A$} \\
\hline PA2015 & \\
\hline 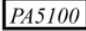 & \\
\hline
\end{tabular}

Figure 4. Identification of PA3458 binding sites in P. aeruginosa. Chromatin immunoprecipitation-sequencing (ChIP-seq) analysis was performed using PAO1161 strain expressing PA3458-FLAG. (A) Distribution of fold enrichment (FE) values for all detected peaks and separately for those identified in intergenic regions or gene body, respectively. FE cut-off value 5 is shown as the red dotted line. In panels B-G, analysis for 319 peaks with FE $>5$ is presented. (B) PseudoCAP analysis of genes with PA3458 binding sites in a promoter, gene body, or terminator (both genes were included in the case of divergent promoters); HUU—hypothetical, unclassified, unknown; CCC—carbon compound catabolism; CWLC—cell wall/LPS/capsule; TPTMD—translation, post-translational modification, degradation; EM—energy metabolism; AABMamino acid biosynthesis and metabolism; PE—putative enzymes; $\mathrm{AP}$ —adaptation, protection; MP—membrane proteins; TSM-transport of small molecules; TR—transcriptional regulators [30]. (C) Overlap between RNA-seq and ChIP-seq analyses. (D) ChIP-seq signal over regions encompassing selected PA3458 binding sites. The plots show coverage with reads for indicated positions in PAO1161 genome, normalized per genome coverage (RPGC) and averaged for ChIP replicates. Genes are presented as blue arrows; only names of PAO1 orthologs are shown for clarity. (E,F) The consensus sequence logos of predicted PA3458 binding sites, obtained by MEME-ChIP $[49,50]$ using the zero or one occurrence per sequence option and sequences corresponding to $200 \mathrm{bp}$ regions around summits of 319 peaks (FE > 5) (motif A, logo built based on 306 sequences) (E), as well as nine peak summits located in promoter regions of regulated genes (marked in Table S4) (motif $\mathrm{A}^{\prime}$, logo built from eight sequences, Table S3) (F). The height of an individual letter represents the relative frequency of the nucleotide at a particular position. The consensus sequence for each motif as well as reverse complement presentation of sequence logos are shown below. (G) Motif sites (motif $\mathrm{A}^{\prime}$ or motif $\mathrm{A}^{*}$ ) identified in promoter regions of regulated genes (statistic is presented in Table S3). 
Table 1. Selected PA3458 binding sites in PAO1161 genome in the proximity of genes showing altered expression in response to PA3458 overproduction

\begin{tabular}{|c|c|c|c|c|c|c|c|c|}
\hline Peak nr & Peak Summit & $\begin{array}{c}\text { Fold } \\
\text { Enrichment }\end{array}$ & Fold Change & Feature * & $\begin{array}{c}\text { PAO1161 } \\
\text { [D3C65_] ID }\end{array}$ & PA01 ID & Gene Name & Gene Product \\
\hline \multirow[b]{2}{*}{296} & \multirow{2}{*}{1650070} & \multirow{2}{*}{27.17} & -3.62 & promoter - & 07825 & PA3459 & \multirow{4}{*}{$\begin{array}{c}\text { fhp } \\
\text { fhpR } \\
\text { (norR) }\end{array}$} & \multirow{4}{*}{$\begin{array}{l}\text { N-acetylglutaminylglutamine amidotransferase } \\
\text { MarR family transcriptional regulator } \\
\text { NO-inducible flavohemoprotein } \\
\text { nitric oxide reductase transcriptional regulator } \\
\text { FhpR (NorR) }\end{array}$} \\
\hline & & & 49.67 & promoter + & 07830 & PA3458 & & \\
\hline \multirow{2}{*}{460} & \multirow{2}{*}{2502004} & \multirow{2}{*}{26.49} & -42.63 & promoter + & 12095 & PA2664 & & \\
\hline & & & -2.05 & promoter - & 12090 & PA2665 & & \\
\hline 1148 & 5940238 & 23.15 & -9.38 & promoter + & 28110 & PA5170 & $\operatorname{arcD}$ & arginine:ornithine antiporter \\
\hline 552 & 3022546 & 11.73 & 2.27 & promoter - & 14200 & PA2264 & & $\begin{array}{l}\text { gluconate 2-dehydrogenase subunit } \\
\qquad 3 \text { family protein }\end{array}$ \\
\hline 758 & 4136054 & 18.41 & 5.03 & promoter - & 19465 & PA1270 & & FUSC family protein \\
\hline 905 & 4819815 & 17.66 & 2.08 & gene body & 22785 & PA4295 & $f p p A$ & type $4 \mathrm{~b}$ pilus Flp prepilin peptidase \\
\hline 913 & 4880773 & 16.55 & -11.11 & promoter - & 23080 & PA4352 & & universal stress protein \\
\hline 731 & 3960512 & 13.75 & -15.23 & promoter - & 18645 & PA1429 & & cation-transporting P-type ATPase \\
\hline 686 & 3777799 & 12.53 & -3.87 & gene body & 17765 & PA1596 & $h t p G$ & molecular chaperone HtpG \\
\hline \multirow[t]{2}{*}{598} & \multirow[t]{2}{*}{3309346} & \multirow[t]{2}{*}{11.61} & -3.39 & terminator + & 15560 & PA2016 & liuR & $\begin{array}{c}\text { MerR family DNA-binding transcriptional } \\
\text { regulator }\end{array}$ \\
\hline & & & -3.09 & promoter + & 15565 & PA2015 & $\operatorname{liu} A$ & isovaleryl-CoA dehydrogenase \\
\hline 770 & 4215905 & 8.68 & -2.01 & terminator - & 19850 & PA1197 & \multirow{2}{*}{ hutU } & hypothetical protein \\
\hline 195 & 1065438 & 6.33 & -2.47 & terminator + & 05130 & PA3971 & & PaaI family thioesterase \\
\hline 555 & 3042187 & 6.20 & -3.60 & gene body & 14290 & PA2247 & $b k d A 1$ & $\begin{array}{l}\text { 3-methyl-2-oxobutanoate dehydrogenase } \\
\text { (2-methylpropanoyl-transferring subunit alpha }\end{array}$ \\
\hline 860 & 4567471 & 6.11 & -2.76 & gene body & 21640 & PA0866 & $\operatorname{aroP2}$ & amino acid permease \\
\hline
\end{tabular}


To identify the DNA sequence preferentially bound by PA3458, a search for recurring DNA motifs was performed using 319 sequences corresponding to $\pm 100 \mathrm{bp}$ around summits of peaks with FE $>5$ using MEME-ChIP [49] with the "zero or one occurrence per sequence" option (Table S4). The 15 bp sequence, with consensus TTHGNASDSRAARDA, hereafter called motif A, was obtained based on 306 sequences from 319 used in the analysis (Figure 4E, Table S3). The motif demonstrated conserved positions with preferred base pairs at positions $1,2,4,11,12$, and 15 . Conducting a similar analysis with nine PA3458 bound loci, upstream of PA3458 regulated genes (marked by a gray background in Table S4), yielded a similar motif (hereafter called motif $A^{\prime}$ ) with the consensus sequence TTTCAGTTGGAAGCA (Figure 4F, Table S3). The motif was based on eight sequences out of nine used in the analysis. Motif $\mathrm{A}^{\prime}$ was not identified in PA1270 promoter; however, this region encompassed a sequence matching the more general motif A (Figure 4G). Motifs identified in 306 peaks from the 319 analyzed are presented in Table S3. The putative binding motifs of PA3458 were located between predicted -10 boxes of promoter sequences and the start codon for $P A 3459$ (Figure 5A), PA2664, and PA2015; upstream of - 35 sequence (PA5170, PA5100) or in a region encompassing -35 and/or -10 box of a predicted promoter sequence (PA2264, PA1270). PA3458 binding to these positions of promoter could potentially modulate the action of the RNA polymerase, hence influencing gene expression.

\subsection{Regulation of Gene Expression by PA3458}

To select conditions for testing the regulatory properties of PA3458 in P. aeruginosa cells, the RT-qPCR analysis of PA3458 level was conducted using RNA from cells harvested at different growth stages. The highest expression of $P A 3458$ was observed in the late logarithmic phase $\left(\mathrm{OD}_{600} \approx 1.0\right)$, indicating a possibility that in this phase, the action of PA3458 might be the most relevant and needed (Figure 5B). The conditions of late logarithmic phase were further exploited in the RT-qPCR analysis to quantify the transcripts level of chosen genes in $\triangle P A 3458$ and WT P. aeruginosa cells. Analysis of PA3459, PA3461, PA5170, PA2204, and PA4352 transcripts level in PA3458-deficient cells showed increased expression relatively to WT cells, while the two other tested genes PA1270 and PA2252 exhibited the decreased expression (Figure 5C). Importantly, for all tested genes, the opposite effect of change of their expression than those observed under conditions of PA3458 excess tested in RNA-seq was observed, confirming the role of PA3458 in their regulation (Table 1).

To verify further the regulatory action of PA3458, the PA3459 promoter region was selected. PA3459 is the first gene of the predicted operon PA3459-PA3461, which is located divergently to the $P A 3458$ gene in $P$. aeruginosa genome (Figure $1 \mathrm{~A}$ ) and showed the decrease in expression in response to PA3458 (Table 1). The divergent promoter PA3458p was also examined to assess the possible autoregulation of $P A 3458$. The two promoter regions were cloned into the probing vector pCM132 carrying promoter-less lacZ (Table A1) [51]. The scheme of PA3458 and PA3459 promoter sequences is shown in Figure 5A. The potential binding motif of PA3458 is located $11 \mathrm{bp}$ downstream of -10 sequence and $76 \mathrm{bp}$ upstream of the start codon in PA3459p and 82 bp down-stream of -10 sequence and 51 bp upstream to the start codon of $P A 3458$.

The pCM132 derivatives pKKB2.31 (PA3458p-lacZ) or pKKB2.32 (PA3459p-lacZ) were introduced into P. aeruginosa PAO1161 and $\triangle P A 3458$ mutant, and the activity of promoters in the late logarithmic phase $\left(\mathrm{OD}_{600} \approx 1.0\right)$ was tested (Figure $\left.5 \mathrm{D}\right)$. The activity of PA3459p was hardly detected and at least 2-fold lower in comparison with PA3458p activity in PAO1161 (Figure 5D). However, the PA3459p activity was significantly higher in the $\triangle P A 3458$ mutant in comparison with the WT strain, indicating possible promoter de-repression in the absence of PA3458. Interestingly, the activity of PA3458p was also higher in the $\triangle P A 3458$ mutant in comparison with the WT strain, which suggests the autoregulatory function of PA3458. 
A

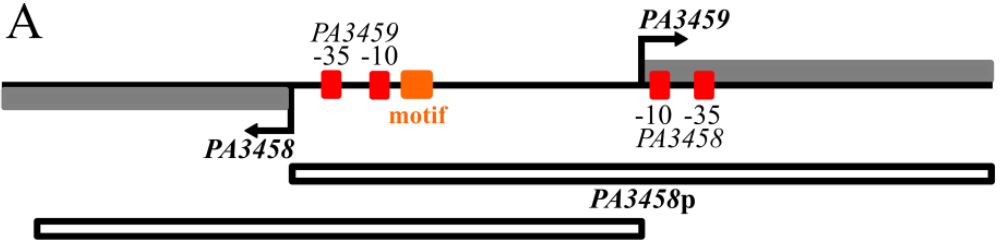

PA3459p

CCGTATCGGCTGAGACGCTTGGAGTGGATTTCGGCGGCCTGCTGGAGACGGCGGATGGCG

CGGAAAATAGCGAGCGAATAGGTATCGGCAGCGGTCTTATTACTTTCAACCATAATAAAT Th $\mathbf{- 3 5} \mathbf{- 1 0}$ motif

GGTCCTCTGTTAGGTAAGTCATGTACCCGGAAGGGGTACGCAACCCACTTCCCCAACGGA GAACCGGTAAGGAATATGTGCGGC

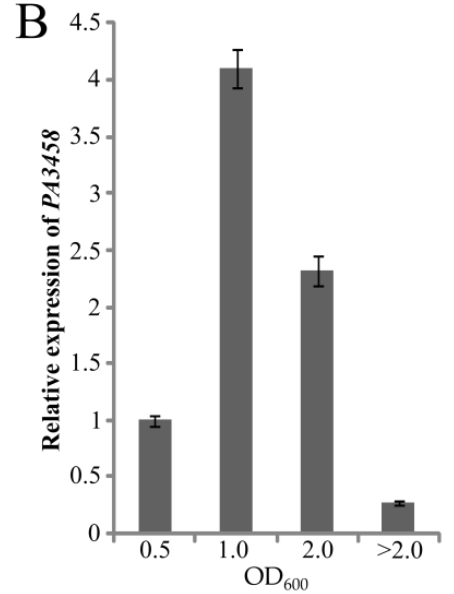

$-35$
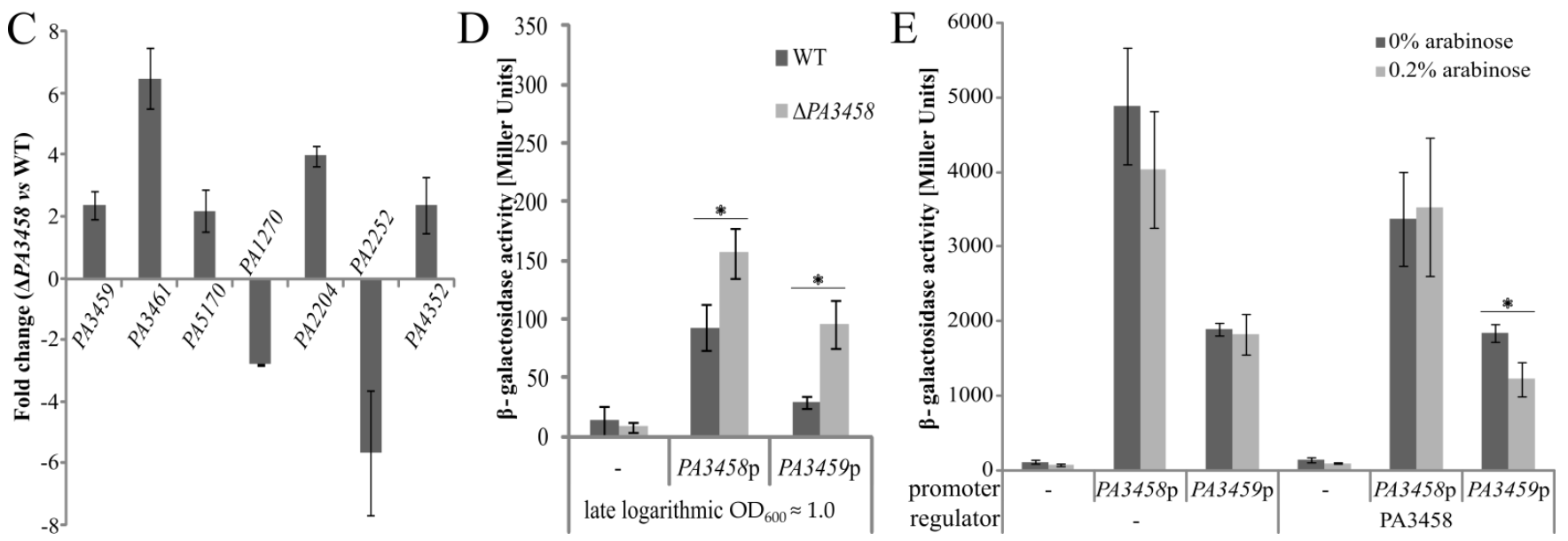

Figure 5. Direct regulation of gene expression by PA3458. (A) The scheme of the PA3458/PA3459 promoter region used in the analysis. The sequence of $P A 3459 \mathrm{p}$ cloned upstream of a promoter-less lacZ reporter gene in pCM132 with marked PA3458 binding motif and predicted -10, -35 promoter sequences are presented below. The fragment beginning from the start codon of PA3459 is also included to show the localization of regulatory elements of PA3458p. (B) Relative expression of PA3458 in PAO1161 in different phases of growth $\left(\mathrm{OD}_{600} \approx 0.5,1.0,2.0\right.$, or $>2.0$ after $\left.24 \mathrm{~h}\right)$. Relative expression presented in comparison to reference gene $n a d B$ and normalized to the level of PA3458 expression in the logarithmic phase OD $_{600}$ $\approx 0.5$ ). Data represent mean expression from three biological replicates. (C) RT-qPCR analysis for chosen genes in $\triangle P A 3458$ and WT tested in late logarithmic phase $\left(\mathrm{OD}_{600} \approx 1.0\right)$. Mean fold change from three biological replicates is presented. The $n a d B$ was used as a reference gene. (D) Regulation of PA3458 and PA3459 promoter in PAO1161 WT or $\triangle P A 3458$ in late logarithmic phase $\left(\mathrm{OD}_{600} \approx 1.0\right)$. Data indicate mean $\beta$-galactosidase activity $\pm \mathrm{SD} .{ }^{*} p<0.01$ in Student's two-tailed t-test. (E) Regulation of PA3459 and PA3458 promoters by PA3458, assayed in E. coli $\Delta$ lac. Cells were transformed with pairs of vector PCM132 and derivatives and vector allowing expression of $P A 3458$ or the empty control vector. $\beta$-galactosidase activity was assayed in five independent transformants grown in medium with or without $0.2 \%$ arabinose.

Concomitantly, to check whether PA3458 regulates PA3458p and PA3459p, E. coli $\triangle$ lac cells were transformed with pCM132 derivatives, pKKB2.31 (PA3458p-lacZ) or pKKB2.32 (PA3459p-lacZ) together with pKKB2.11 (araBADp-PA3458), which are used for the production of PA3458 or the corresponding empty vector. The $\beta$-galactosidase activity measurements in extracts from stationary E. coli $\Delta$ lac cells showed that under tested conditions, the activity of $P A 3458 \mathrm{p}$ was at least two times higher than that of $P A 3459 \mathrm{p}$ (Figure $5 \mathrm{E}$ ). When PA3458 was produced, a similar trend was observed. The overproduction of PA3458, by the addition of arabinose to the cultures, had no effect on the expression from PA3458p, but it significantly diminished the PA3459p-lacZ expression, indicating the repression of PA3459p by PA3458. 


\subsection{Phenotypic Characterization of PAO1161 $\triangle P A 3458, \triangle P A 3459$, and $\triangle P A 3459-P A 3461$ Strains}

Our studies point out the role of PA3458 in gene expression regulation in P. aeruginosa (Tables S1-S3), including negative regulation of the PA3459 gene, which is part of the $P A 3459-P A 3461$ operon that is transcribed divergently to PA3458. This operon encodes asparagine synthase (PA3459), GNAT-family acetyltransferase (PA3460), which is involved in the production of osmoprotectant N-acetylglutaminylglutamine amide (NAGGN) and hypothetical glutamyl aminopeptidase (PA3461) [9,52]. Previously, comparative microarray analysis showed that the PA3459-PA3461 genes but not $P A 3458$ were up-regulated in $P$. aeruginosa cells in response to osmotic stress [9]. Concomitantly, analysis of the growth of $P$. aeruginosa $\triangle P A 3459$ and $\triangle P A 3460$ mutants in a medium with either $0.5 \mathrm{M} \mathrm{NaCl}$ or $0.7 \mathrm{M}$ sucrose, representing conditions of osmotic stress showed that the absence of these genes negatively affects the growth of the cells in these conditions [9].

To investigate the significance of the PA3458 mediated regulation of PA3459-PA3461 operon under osmotic stress, the $\triangle P A 3458, \triangle P A 3459$, and $\triangle P A 3459-P A 3461$ PAO1161 mutants, as well as WT, were cultivated in minimal A medium with or without $0.5 \mathrm{M}$ $\mathrm{NaCl}$ or $0.7 \mathrm{M}$ sucrose. No visible changes in bacterial growth between WT PAO1161 and mutants were observed in MA medium without $\mathrm{NaCl}$ or sucrose (Figure $6 \mathrm{~A}$ ). However, under conditions of osmotic stress, either in the presence of $0.5 \mathrm{M} \mathrm{NaCl}$ or $0.7 \mathrm{M}$ sucrose, the $\triangle P A 3458$ mutant showed repetitively better growth than WT, while the $\triangle P A 3459$ and $\triangle P A 3459-P A 3461$ mutants grew much slower, which was likely caused by the impaired production of NAGGN (Figure 6B,C). The effect of faster growth observed for PAO1161 $\triangle P A 3458$ strain under osmotic stress in comparison to WT cells might be explained by the higher expression of $P A 3459-P A 34561$ in mutant cells, which is due to the lack of repression by PA3458, which allows better adaptation to osmotic stress. Interestingly, since one of the roles PA3458 plays in P. aeruginosa is the repression of the PA3459-PA3461 operon, it seems that under standard, non-osmotic stress conditions, the repression of PA3459-PA3461 operon is a more favourable state than its constant expression. In addition, the PA3459 mutation has less effect on growth than the deletion of PA3459-PA3461 operon, indicating that the inactivation of one gene is less deleterious that deletion of the whole operon for the cell at tested conditions.
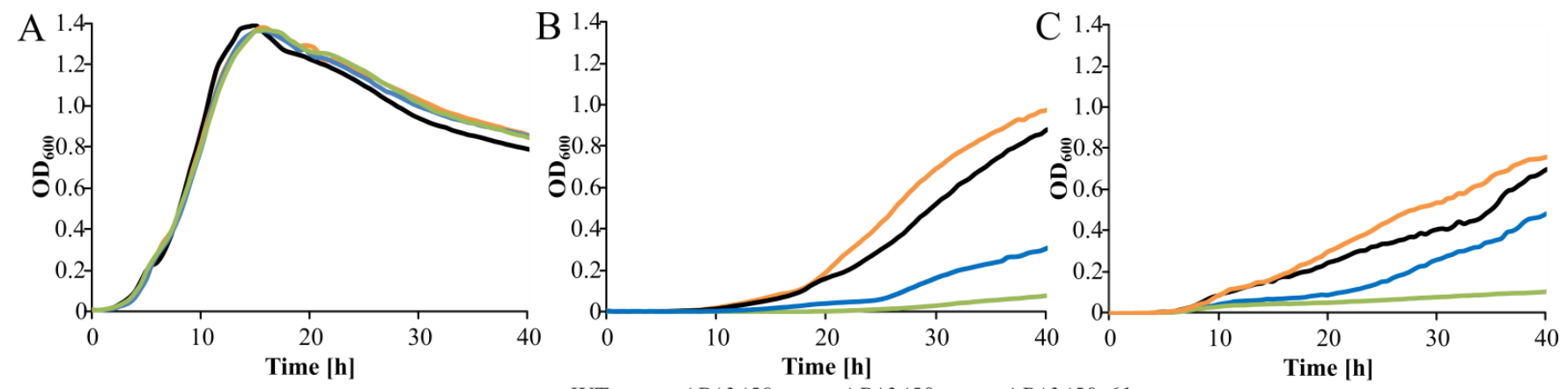

- WT $-\triangle P A 3458-\triangle P A 3459-\triangle P A 3459-61$

Figure 6. Phenotypic characterization of P. aeruginosa mutants in PA3458-PA3461 genes. Growth of P. aeruginosa PAO1161 derivatives (WT, $\triangle P A 3458, \triangle P A 3459$, and $\triangle P A 3459-P A 3461$ ) in minimal A medium with glucose (A) and supplemented with $0.5 \mathrm{M} \mathrm{NaCl}(\mathbf{B})$ or $0.7 \mathrm{M}$ sucrose $(\mathbf{C})$. Data represent mean $\mathrm{OD}_{600}$ from six cultures. Standard deviations were less than $15 \%$ and are not shown for clarity.

\subsection{Distribution and Evolutionary Conservation of PA3458-PA3461 Cluster in Bacteria}

Previous studies showed that homologs of PA3459 and PA3460 genes, the asnO-ngg cluster, and their organization are conserved among many divergent bacterial species [52]. The presence of genes encoding orthologues of PA3458-PA3461 together with a MarR-type transcriptional regulator similar to PA3458 was analyzed in available bacterial genomes using MultiGeneBlast [53]. This analysis yielded 22 genomes encoding orthologs of all four proteins with the same (except one Magnetococcus marinus MC-1) genes arrangement 
(Figure A3, Table S5). Fifty-two genomes encode the operon without regulatory genes, and 17 (mainly Mycobacterium sp.) code for PA3459-PA3460 (Table S5). The 31-71\%, 56-83\%, $51-82 \%$, and $49-84 \%$ identity of amino acid sequences was observed for homologues of PA3458, PA3459, PA3460, and PA3461, respectively, indicating the strong evolutionary conservation of enzymes and a bit lower for the regulator.

Nine strains encoding the PA3458-PA3461 cluster belong to the genus Pseudomonas and seven are classified to the alpha-proteobacteria (Table S5). The identified strains represent different lifestyles, including pathogenic bacteria (plant or human) or strains isolated from an environment with high salinity such as seawater or saline soil. Interestingly, the PA3458-PA3461 cluster was not conserved in so-called "honorary Pseudomonads", which are species sharing similar metabolism and lifestyles although phylogenetically classified at some distance, e.g., in beta-proteobacteria from the Burkholderia or Ralstonia species, which often exchange genetic material with Pseudomonas bacteria [54]. The cluster was identified in some Pseudomonads, Azotobacter and alpha-proteobacteria from highsaline habitats, pointing out the need of osmoprotection and osmoadaptation functions in inhabited environments and the pressure to preserve genes encoding them.

When the genes encoding the orthologs of the PA3458 transcriptional regulator from 21 strains (Table S5) were aligned and their evolutionary distance was analyzed (Figure A3), the most similar gene to PA3458 was the TR from P. citronellolis SJTE-3, which is a strain that was isolated from sludge.

These results indicate that the presence of genes encoding PA3458-PA3461 proteins is not unique to PAO1/ PAO1161 or Pseudomonas sp. and occurs in other bacteria. For some of them, the correlation of the gene cluster occurrence with living in a high salinity environment could be noticed.

\section{Discussion}

The PA3458 protein belongs to the MarR family of transcriptional regulators [19]. In this study, the transcriptional profiling of cells overproducing PA3458 was performed, indicating 133 genes with altered expression. Concomitantly, more than 300 binding sites scattered in $P$. aeruginosa genome were identified, which highlights the great modulatory and/or regulatory potential of the PA3458 protein and may partially explain why its overproduction acts negatively on P. aeruginosa cells, leading to a cessation of bacterial growth

Comparison of the genes with altered expression in response to PA3458 excess and PA3458 binding sites pointed out nine identified PA3458 binding sites upstream of regulated genes. The genes, potentially directly regulated by PA3458 encode proteins with a predicted function in stress response e.g., PA2664 (Fhp), PA2665 (FhpR), PA1429, PA1270, PA4352, PA2264, and amino acid metabolism PA3459, PA5170 (ArcD), PA5100 (HutU), PA2015 (LiuA), PA2016 (LiuR), and PA0866 (AroP2).

Among these, the PA3458 binding site with the highest fold enrichment was found in the promoter region of the PA3459-PA3461. RNA-seq analysis showed significantly decreased expression of PA3459-PA3461 genes in response to PA3458 excess (Table 1), which indicates that PA3458, similar to many other TRs [55], regulates the divergent operon. The PA3459-PA3461 operon encodes proteins involved in the production of a potent osmoprotectant: $\mathrm{N}$-acetylglutaminylglutamine amide (NAGGN), conferring bacterial cells resistance to osmotic stress [9,52].

The PA3459 and PA3460 are homologues of AsnO and Ngg proteins from S. meliloti [52]. They are involved in a non-ribosomal synthesis of dipeptide NAGGN. In the first step, the $\mathrm{Ngg}$ catalyzes both the $\mathrm{N}$-acetylation of one glutamine and the formation of a peptide bond with a second glutamine, producing the intermediate-NAGG-N-acetylglutaminylglutam ine [52]. The AsnO transfers the amide nitrogen of another free glutamine to the second glutamine of NAGG, creating NAGGN [50]. This compound was detected in osmotically stressed cultures of P. aeruginosa, along with known osmoprotectants such as glutamate or trehalose [56]. At higher $\mathrm{NaCl}$ concentrations, NAGGN became the dominant osmolyte in P. aeruginosa [56]. 
MultiGeneBlast analysis showed that analogous genes arrangement for orthologs of a MarR-type regulator (PA3458) and divergent operon was found in at least 21 other strains with different lifestyles, including pathogens (Figure A3; Table S5). Interestingly, clustered genes encoding orthologs of P. aeruginosa PA3459-PA3461 were found in 52 other bacterial genomes. A closer inspection of their neighboring genes did not indicate the presence of transcriptional regulators; hence, it is likely that they are under the regulation of other factors encoded in trans. In P. aeruginosa cells, the highest mRNA level of PA3458 was detected in cells from the late logarithmic phase of growth. Our studies demonstrated the role of PA3458 in PA3459-PA3461 repression. Why do these genes need to be repressed and tightly controlled in the cell? The simplest answer is that gene expression control is the most economical way to save resources. The enzymes encoded by PA3459-PA3461 to produce NAGGN consume three glutamines and one acetyl-CoA [52]. Thus, uncontrolled production of NAGGN may deplete the cellular glutamine pool, and its availability is crucial for many cellular processes.

PA3458 acts as a repressor of the asnO-ngg genes, allowing modulation of their expression depending on growth conditions and possibly regulating the NAGGN pool during adaptation to osmotic fluctuations. Such variations could be also the part of intracellular changes accompanying the transition between the logarithmic and stationary phases of growth. This may partially explain the changes in PA3458 expression dependent on a growth phase (Figure 5B). A comparison of logarithmically and stationary growing WT PAO1161 cells indicated the lower expression of PA3458 and concomitant higher expression of PA3459-PA3461 in stationary phase cultures (Bartosik AA et al., in preparation). Interestingly, a similar expression pattern was observed for the slyA gene of $S$. typhimurium, which encodes the global regulator playing a crucial role in survival in the intra-phagosomal environment and in resistance to macrophage killing [43,57].

In the proposed model of action, the PA3458 protein binds to the promoter region of $P A 3459$ gene and represses its expression. This negative regulation is released when the conditions of growth change for example by increasing the osmolarity of an environment, allowing the production of NAGGN osmoprotectant. It helps sensitively adjust the expression of the $a s n O$ and $n g g$ in the cells. We hypothesize that the increasing concentration of ions, e.g., $\mathrm{Na}^{+}, \mathrm{K}^{+}$, and/or binding of unknown ligand causing allosteric inhibition may modulate PA3458 activity, e.g., its inability to interact with DNA, which triggers de-repression of the PA3459-PA3461 operon. Many MarR-type transcriptional regulators are allosterically inhibited [55]. Additionally, the changes in DNA structure and/or topology, e.g., supercoiling, which are observed under osmotic stress conditions or the transition to stationary phase may also influence PA3458 interaction with DNA [58-60]. The specific requirements for DNA binding by PA3458 are supported by the observation that despite numerous tries, setups, and multiple conditions tested, we failed to demonstrate any PA3458 binding to DNA using electrophoretic mobility shift assays (EMSA, data not shown).

The action of PA3458 is not limited to one target. More than 300 PA3458 binding sites were identified in P. aeruginosa genome, indicating broad protein interactions with DNA. The motif sequence bound preferentially by PA3458 was identified, and it is characterized by AT-rich regions at both ends resembling in part a palindromic structure with a variable center (Figure 4E,F). A more specific motif sequence recognized by PA3458 was identified, when PA3458 binding sites with the highest fold enrichment in ChIP-seq analysis and detected in promoter regions of regulated genes were analyzed. This may suggest the evolutionary pressure to maintain preferred nucleotide positions in sequences recognized by PA3458 to exert a stronger effect on gene regulation. Although the motif is not strictly palindromic it resembles in part a palindromic structure with preferred double $\mathrm{T}$ and A base pairs at positions 1,2 and 11,12, respectively of the proposed motif with a more flexible center in between these positions and additional extension with conserved $\mathrm{A}$ at position 15 . In motif $\mathrm{A}^{\prime}$, more positions tend to be conserved, and the partial palindromic structure within the first 12 base pairs positions of the motif is even more evident, as 
presented by underlined positions marked by // indicating the plane of symmetry in the consensus sequence TTTCAG//TTGGAA GCA presented in Figure 4F. The identified motif resembles the MarR-type regulator SlyA binding site TTAGCAAGCTAA [43]. It is worth mentioning that also non-perfectly palindromic sequence motifs bound by MarR-type transcriptional regulators were found e.g., for MalR from Corynebacterium glutamicum, consensus TTnAAnnnTCAA [61]; HpaR from Xanthomonas campestris-consensus [G/T]CAACAATT[C/T]TTG [62] or CosR from Vibrio parahaemolyticus-consensus TTTGANN-TCTAA [63].

For some PA3458 binding sites identified in the promoters of down-regulated genes (PA3459, PA2664, PA2015, PA4352, PA1429), the motif is located upstream of the start codon and often downstream of -10 promoter sequence; thus, it is in a position to interfere with RNA polymerase action. In the case of PA2264 and PA1270 promoters potentially stimulated by PA3458, the binding motif encompass -35 or -10 promoter sequences, respectively, possibly positively influencing RNAP activity. It is not excluded that regulator binding to the site in the coding region may also exert the effect on gene expression regulation as exemplified by PA1596, PA2247, or PA0866 as target genes of PA3458, but the molecular mechanism of gene expression control in this way requires further studies.

The weaker PA3458 interactions with less conserved binding sites scattered in $P$. aeruginosa genome were also detected, and it is not excluded that under special growth conditions, such interactions may also be part of the regulatory network [55]. Many MarR regulators are biosensors and bind to DNA or dissociate from it under specific conditions e.g., changes in oxidation level, $\mathrm{pH}$, or sensing chemical signals [19]. These data indicate that specific DNA binding by PA3458, similar to other MarR-type transcriptional regulators, may require not only specific sequence but also other factors.

The study showed that PA3458 may potentially control the expression of genes other than the divergently encoded operon. The fhp (PA2664) gene with a strong PA3458 binding site in the promoter region (FE > 26) was 42-fold down-regulated in PA3458+ cells. It encodes the flavohemoprotein Fhp necessary to protect bacterial cells from nitrosative stress by detoxifying NO to nitrate $[64,65]$ and induced in response to NO [66]. The expression of $f h p R$ (PA2665) encoded divergently to $f h p$ and encoding the transcriptional activator of fhp [64] was also 2-fold down-regulated in PA3458+.

The other gene whose expression was significantly diminished in response to PA3458 is PA1429 encoding a probable cation-transporting P-type ATPase. The PA1429 inhibits Pseudomonas quinolone signal (PQS) synthesis and influences bacterial motility, biofilm formation, or virulence [67].

The PA3458 binding site was detected in the promoter region of the $\operatorname{arc} D A B C$ operon, which also responded by a decrease in expression in response to PA3458. The arc operon encodes proteins involved in anaerobic arginine catabolism in P. aeruginosa $[68,69]$. The deletion mutant in the $\operatorname{arcD}$ gene exhibited increased bacterial motility, biofilm formation, and virulence in a mouse model of acute lung infection [69]. Arginine is shown as a killing enhancer by ciprofloxacin and tobramycin under anaerobic, but not aerobic, growth conditions $[68,69]$. This indicates that regulation of the stress response by PA3458 may extend beyond the control of NAGGN production.

In P. aeruginosa, the extensive transcription regulatory network allows complex and precise response to changes in the environment. It is not surprising that some PA3458dependent genes are also parts of other regulons and are co-regulated by other regulatory proteins: e.g., the $\operatorname{arc} D A B C$ operon by a nitrate-responsive NarX-NarL regulator [70]; the pauA4 by PauR [71]; the fhp by PA3697 [72]; the liuR, liuA by Hfq-Crc [73] or PA4352 by Anr [74]. The analysis presented here adds a new player to the existing network.

To summarize, this study showed that the representative of the MarR-type regulators PA3458 is involved in gene expression control in P. aeruginosa. Many binding sites of the protein were identified in P. aeruginosa genome predisposing PA3458 to play a role as the global regulator, with one of the direct targets engaged in the production of bacterial 
osmoprotectant NAGGN. The activity of PA3458 and its target genes may play a role in an adaptation of bacterial cells to changing growth conditions, including osmotic stress.

\section{Materials and Methods}

\subsection{Growth Conditions, Bacterial Strains, and Plasmids Manipulations}

Bacterial strains and plasmids used in this study are listed in Table A1. P. aeruginosa PAO1161 strain [48], a derivative of PAO1 possessing mutations in leuA, PA2735, and rpoB genes connected with $l e u^{-}, r^{-}$, Rif ${ }^{\mathrm{R}}$ phenotypes, respectively, was used in most experiments except for those conducted in minimal media, in which $l e u^{+}$derivative of PAO1161 was used (Table A1). The PAO1161 strain carries ICEPae1161, which is a functional PAPI-1 family integrative conjugative element conferring mercury resistance [48], but this element should not have influence on the outcome of experiments described in this manuscript.

Bacterial strains were grown in Luria-Bertani (LB) broth, minimal media MA, and M9 or on LB plates containing $1.5 \%(w / v)$ agar [75]. For the selection of plasmids, LB medium was supplemented with appropriate antibiotics: kanamycin $\left(50 \mu \mathrm{g} \mathrm{mL}{ }^{-1}\right.$ for E. coli, $500 \mu \mathrm{g} \mathrm{mL}^{-1}$ in solid media, and $250 \mu \mathrm{g} \mathrm{mL}^{-1}$ in liquid media for P. aeruginosa); benzylpenicillin sodium salt $\left(300 \mu \mathrm{g} \mathrm{mL} \mathrm{m}^{-1}\right.$ in solid media and $150 \mu \mathrm{g} \mathrm{mL}^{-1}$ in liquid media for E. coli); carbenicillin $\left(300 \mu \mathrm{g} \mathrm{mL}^{-1}\right.$ for $P$. aeruginosa); rifampicin $\left(300 \mu \mathrm{g} \mathrm{mL}^{-1}\right.$ for P. aeruginosa); chloramphenicol $\left(10 \mu \mathrm{g} \mathrm{mL}^{-1}\right.$ for E. coli, $150 \mu \mathrm{g} \mathrm{mL}^{-1}$ for P. aeruginosa). Plasmid DNA isolation, manipulation, and transformation into competent cells of E. coli was conducted prepared by the $\mathrm{CaCl}_{2}$ method [76].

Cultures for RNA-seq, ChIP-seq, and RT-qPCR analyses were conducted in flasks closed with a cotton plug, filled with medium to $20 \%$ of volume. Cultures were incubated at $37^{\circ} \mathrm{C}$ with shaking $200 \mathrm{rpm}$.

Kinetics of growth were analyzed at $37^{\circ} \mathrm{C}$ upon 100 -fold dilution of the overnight cultures in LB, washed with the appropriate medium in LB, minimal medium MA, or M9 with various additives, such as $0.25 \%$ citrate or $17 \mathrm{mM}$ glucose as a carbon source and $0.5 \mathrm{M}$ $\mathrm{NaCl}$ or $0.7 \mathrm{M}$ sucrose [9,76]. Bacterial growth in 96-well plates was monitored by measurements of optical density at $600 \mathrm{~nm}\left(\mathrm{OD}_{600}\right)$ using a Varioskan Lux Multimode Microplate Reader and SkanIt RE 6.0.2 software (Thermo Fisher Scientific, Waltham, MA, USA).

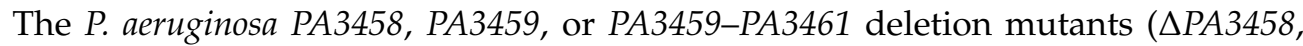
$\triangle P A 3459$, or $\triangle P A 3459-61)$ were constructed by allele exchange using the pAKE600 suicide vector derivatives [77]: pKKB2.61, pKKB2.62, and pKKB2.63 (Table A1). The upstream and downstream DNA fragments of mutated regions were amplified using selected primers (1\#/2\# pair and 3\#/4\# pair for PA3458,5\#/6\# pair and 7\#/8\# for PA3459 or 5\#/6\# pair and 9\#/10\# for PA3459-PA3461) (Table A2). The PCR products, corresponding to upstream and downstream regions were digested with BamHI, HindIII and HindIII, EcoRI, respectively, and both fragments were ligated with EcoRI, BamHI digested pAKE600. E. coli S17 strain, carrying suicide plasmids was conjugated with the recipient strain P. aeruginosa PAO1161 $\left(\right.$ Rif $\left.^{R}\right)$. Putative cointegrants were selected on LB agar with rifampicin and carbenicillin. The vector removal by second recombination was conducted by growing the cells in LB with $10 \%$ sucrose. Colonies with exchanged alleles were selected by PCR.

Motility (swimming, swarming) assays were performed as described previously [38,76] for PAO1161 and $\triangle P A 3458$ mutant for $24 \mathrm{~h}$ at $37^{\circ} \mathrm{C}$. Plates were standardized by using the same volume of each medium.

Biofilm analysis was performed on LB or minimal medium with citrate. Cultures were grown for $24 \mathrm{~h}$ and $48 \mathrm{~h}$ at $37^{\circ} \mathrm{C}$, respectively. The measurements were carried out according to the previously described method [76].

\subsection{Construction of Expression Vectors and Protein Purification}

To obtain vectors allowing the production of PA3458 His $_{6}$-tagged at the N- or Cterminus, the gene was cloned in pET28a (Novagen). To construct the his $_{6}$-PA3458 fusion, PA3458 was amplified by PCR with the use of 11\#/12\# primer pair and PAO1161 genomic DNA as a template. The product was digested with EcoRI, SacI, and ligated with EcoRI, 
SacI digested pET28a to obtain pKKB2.21. Similarly, to obtain PA3458-his 6 fusion, PCR fragment amplified using a 13\#/14\# primers pair was digested with NcoI, HindIII, and ligated with pET28a digested with NcoI, HindIII to yield pKKB2.22.

Overproduction of $\mathrm{His}_{6}-\mathrm{PA} 3458$ and $\mathrm{PA}_{3458-\mathrm{His}_{6}}$ prior purification was carried out in E. coli BL21 carrying pKKB2.21 or pKKB2.22, respectively. The overnight cultures of transformants were diluted 1:50 in $500 \mathrm{~mL} \mathrm{LB}$ with kanamycin and grown for $1 \mathrm{~h}$ at $37^{\circ} \mathrm{C}$. Protein expression was induced with $0.5 \mathrm{mM}$ isopropyl $\beta$-D-1-thiogalactopyranoside (IPTG), and the cultures were grown at $37^{\circ} \mathrm{C}$ for $4 \mathrm{~h}$. Cells were harvested by centrifugation, and the pellet was resuspended in LEW buffer $\left(50 \mathrm{mM} \mathrm{NaH}_{2} \mathrm{PO}_{4}, 300 \mathrm{mM} \mathrm{NaCl} \mathrm{pH}=8\right)$ with $1 \mathrm{mM}$ protease inhibitor phenylmethylsulfonyl fluoride (PMSF) and $1 \mathrm{mg} \mathrm{ml}^{-1}$ lysozyme. After $0.5 \mathrm{~h}$ incubation on ice, the mixture was sonicated and cleared by centrifugation. The supernatant was collected and applied on Ni-agarose columns (Ni-TED 1000 Protino, Marchel\&Nagel), followed by washing using $20 \mathrm{~mL}$ LEW and eluated using $4 \times 1 \mathrm{~mL}$ LEW with $250 \mathrm{mM}$ imidazole. The purification procedure was monitored by sodium dodecyl sulfate (SDS) polyacrylamide gel electrophoresis (PAGE) with a Pharmacia PHAST gel system. Elution fractions with the highest concentration of proteins were dialyzed against LEW buffer with $10 \%$ glycerol. Small aliquots of the purified protein were stored at $-80{ }^{\circ} \mathrm{C}$ for further analysis.

To obtain an expression vector allowing expression in P. aeruginosa, the PA3458 gene was amplified using 11\#/12\# primer pair, EcoRI, SacI digested, and ligated with EcoRI, SacI digested pKGB8, downstream of arabinose regulated araBADp to yield pKKB2.11. This plasmid was introduced to P. aeruginosa PAO1161 and E. coli DH5 $\alpha$ to test the effects of protein overproduction at various concentrations of the inductor (arabinose).

To obtain PA3458-flag translational fusion, the PA3458 sequence was cloned using the PCR amplified fragment with \#11/\#15 primers and ligated to PKAB20B vector (with flag-tag) after EcoRI, BamHI digestion. Then, the PA3458-flag fragment was excised using EcoRI and SalI and then cloned into pKGB8 to obtain pKKB2.12.

\subsection{Glutaraldehyde Crosslinking}

The oligomerization state of purified $\mathrm{His}_{6}-\mathrm{PA} 3458$ and $P A 3458$-His 6 was assayed by crosslinking using glutaraldehyde in concentration up to $0.05 \%$ in a buffer composed of $50 \mathrm{mM} \mathrm{N}, \mathrm{N}$-Bis(2-hydroxyethyl)glycine- $\mathrm{NaOH}$ (BICINE-NaOH); $0.1 \mathrm{mM}$ ditiotreitol (DTT), and $0.4 \mathrm{M} \mathrm{NaCl}$. For each $20 \mu \mathrm{L}$ reaction, $2 \mu \mathrm{g}$ of protein was used. After $20 \mathrm{~min}$, the reaction was stopped by adding ethanolamine- $\mathrm{HCl}(\mathrm{pH} 8)$ to a final concentration of $0.14 \mathrm{M}$. Samples were analyzed using SDS-PAGE, and the protein was visualized by immunodetection, using anti-His antibodies after the transfer onto a nitrocellulose membrane.

\subsection{SEC-MALS Analysis}

Size exclusion chromatography coupled to multi-angle light scattering (SEC-MALS) analysis was performed using a high-performance liquid chromatography (HPLC) instrument (1260 Infinity LC, Agilent Technologies Inc., Santa Clara, CA, USA) equipped with a UV detector, a MALS detector (DAWN HELEOS II, Wyatt Technology, Santa Barbara, CA, USA), and a differential refractometer (Optilab T-rEX, Wyatt Technology, Santa Barbara, CA, USA). Then, $100 \mu \mathrm{L}$ of $1 \mathrm{mg} \mathrm{ml}^{-1}$ samples were loaded onto a Superdex 200 Increase 10/300 column (GE Healthcare, Milwaukee, WI, USA) equilibrated with LEW buffer. Absorption at 280, 254, and $215 \mathrm{~nm}$ was monitored during SEC. Samples were run at room temperature at a flow rate of $0.5 \mathrm{~mL} \mathrm{~min}^{-1}$. The results were analyzed using ASTRA v. 6 software (Wyatt Technology, Santa Barbara, CA, USA) in accordance with the manufacturer's instructions.

\subsection{RNA Isolation, RNA-seq, and RT-qPCR Analysis}

Strains were obtained by transformation of PAO1161 with pKKB2.11 (araBADp-PA3458) or pKGB8 (araBADp) plasmids (Table A1). Transformants were selected on LB plates supplemented with $150 \mu \mathrm{g} \mathrm{mL}^{-1}$ chloramphenicol and were verified by isolation of plasmid 
DNA and its digestion. After overnight growth, each of three cultures were diluted 1:100 into fresh LB supplemented with $75 \mu \mathrm{g} \mathrm{mL} \mathrm{mL}^{-1}$ chloramphenicol and $0.02 \%$ arabinose. Cells were collected from $2 \mathrm{~mL}$ of cultures in the logarithmic phase of growth (optical density at $600 \mathrm{~nm}$ of $0.4-0.6$ ) and mixed with $4 \mathrm{~mL}$ of RNAprotect Bacteria Reagent (Qiagen, Hilden, Germany). RNA was isolated using the Qiagen RNeasy Mini Kit, according to the manufacturer's instructions. Isolated RNA was treated with a DNA-free DNA Removal Kit (Invitrogen, Thermo Fisher Scientific, Waltham, MA, USA), and a lack of DNA contamination was checked by PCR. RNA concentration was determined using a $\mu$ Drop plate of Varioskan Lux Multimode Microplate Reader and quality was checked using Bioanalyzer. Library preparation and sequencing were performed in the Genomed S.A., Warsaw, Poland. rRNA was depleted using Ribo-Zero ${ }^{\mathrm{TM}}$ rRNA Removal Kit (Bacteria) (MRZMB126, Illumina, San Diego, CA, USA) according to manufacturer instructions. Libraries were prepared according to instructions accompanying the NEBNext ${ }^{\circledR}$ Ultra $^{\mathrm{TM}}$ DNA Library Prep Kit for Illumina (E7370S, New England Biolabs, Ipswich, MA, USA).

Libraries were sequenced using standard Illumina protocols (NextSeq500, paired-end with 150 cycles for each read). Reads were quality-checked and filtered using FASTP version 0.20.0 [78] and mapped to P. aeruginosa PAO1161 genome (CP032126.1) using Bowtie2 version 2.3.4.3 [79] with default settings. The number of reads mapping to individual genes was counted using FeatureCounts v 2.0.1 (part of the Subread) with the -s2 option [80]. Differential expression analysis was conducted using edgeR ver 3.28.0 [81]. Raw data are available in the NCBI's Gene Expression Omnibus (GEO) database (http: / www.ncbi.nlm. nih.gov / geo/, accesses on 20 February 2021) under accession number GSE167147.

For qRT-PCR analyses, cells from PAO1161 WT and $\triangle P A 3458$ mutant cultures were

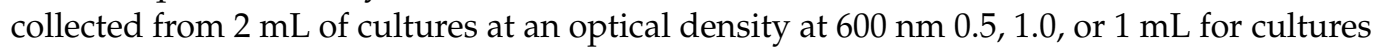
with an optical density at $600 \mathrm{~nm}$ of 2.0 or after $24 \mathrm{~h}$. RNA for qRT-PCR was isolated identically as for RNA-seq analysis. Reverse transcription was performed with $4 \mu \mathrm{g}$ of RNA using the TranScriba Kit (A\&A Biotechnology, Gdansk, Poland). qPCR was performed on a LightCycler 480 II System (Roche Molecular Diagnostics, Mannheim, Germany) using $5 \times$ HOT FIREPol EvaGreen qPCR Mix Plus (Solis Biodyne, Tartu, Estonia). Each $18 \mu \mathrm{L}$ reaction contained $3.6 \mu \mathrm{L} 5 \times$ reaction mix, $1 \mu \mathrm{L}$ of five times diluted $\mathrm{cDNA}$, and $1.5 \mu \mathrm{L}$ of mixed $5 \mu \mathrm{M}$ primers. The relative expression was determined by a comparison of crossing points $(\mathrm{Cp})$ between the target and the reference gene (proC or nadB). Three technical repetitions were used for each primer pair. The ratio/fold change was calculated using Pfaffl's formula [82].

\subsection{Chromatin Immunoprecipitation with Sequencing (ChIP-seq)}

ChIP-seq analysis was performed on PAO1161 $\triangle P A 3458$ strain overproducing PA3458FLAG (pKKB2.12) [PA3458-F+] as well as the strain carrying the empty vector pABB28.3 (background control) in LB containing $50 \mu \mathrm{g} \mathrm{mL}^{-1}$ chloramphenicol. Four independent overnight cultures from each strain were inoculated and diluted 1:100 in LB supplemented with $75 \mu \mathrm{g} \mathrm{mL}{ }^{-1}$ chloramphenicol and $0.02 \%$ arabinose. Bacteria were grown at $37^{\circ} \mathrm{C}$ until reaching the exponential phase with optical density at $600 \mathrm{~nm}\left(\mathrm{OD}_{600}\right)$ about 0.5 .

ChIP protocol was based on a modified S. Schulz and S. Haussler protocol using Dynabeads Protein A [83]. The procedure was performed as described earlier until the step of sonication [84]. Lysate after sonication was thawed on ice, and $150 \mu \mathrm{L}$ of each strain variant was incubated with $20 \mu \mathrm{L}$ of magnetic beads coupled with protein A (Dynabeads Protein A, Invitrogen, 10001D), which was separated from original suspension using a Magnetic Separation Stand. The pre-clearing step was performed for $1 \mathrm{~h}$ at $4{ }^{\circ} \mathrm{C}$ with a rotation of the mixtures. Then, $50 \mu \mathrm{L}$ of magnetic beads, separated from the suspension as above, was mixed with $6 \mu \mathrm{L}$ of anti-FLAG mouse polyclonal antibodies (DYKDDDDK Tag polyclonal antibodies; PA1-985B; Invitrogen (Thermo Fisher Scientific, Waltham, MA, USA); $1 \mathrm{mg} \mathrm{mL}^{-1}$ ) diluted in $200 \mu \mathrm{L}$ of PBS (phosphate buffered saline) with $0.05 \%$ Tween-20. Mixtures of magnetic beads and antibodies were incubated for $10 \mathrm{~min}$ at $4{ }^{\circ} \mathrm{C}$ with gentle rotation. Then, beads with bound antibodies were separated from the supernatant, washed 
once with $200 \mu \mathrm{L}$ of the PBS with $0.05 \%$ Tween-20 solution, and stored on ice. Pre-cleared lysate was separated from the beads and added to the beads coated with antibodies. A mixture containing lysate and magnetic beads with antibodies was incubated at $4{ }^{\circ} \mathrm{C}$ for 20 min with mixing on a rotator. Then, beads were collected and washed as described earlier [84]. Elution was performed twice for $15 \mathrm{~min}$ in $50 \mu \mathrm{L}$ at $65{ }^{\circ} \mathrm{C}$ in a thermoblock with shaking $(1400 \mathrm{rpm})$. Elutions from 6 parallel reactions were pooled and then $30 \mu \mathrm{L}$ pipetted for Western blot analysis. The rest of the obtained eluates were incubated with $8 \mu \mathrm{L}$ of RNase A (100 mg mL ${ }^{-1}$, 19101, Qiagen, Hilden, Germany) for $30 \mathrm{~min}$ at $65^{\circ} \mathrm{C}$. Then, $40 \mu \mathrm{L}$ of Proteinase K (20 mg mL ${ }^{-1}, 19133$, Qiagen) was added, and the samples were incubated for $1 \mathrm{~h}$ at $50{ }^{\circ} \mathrm{C}$ followed by overnight incubation at $65^{\circ} \mathrm{C}$. Next, $40 \mu \mathrm{L}$ of Proteinase $\mathrm{K}$ was added, and the samples were again incubated for $1 \mathrm{~h}$ at $50^{\circ} \mathrm{C}$. Subsequently, $24 \mu \mathrm{L}$ of $3 \mathrm{M}$ sodium acetate ( $\mathrm{pH} 5$ ) was added, and the volume was adjusted to $700 \mu \mathrm{L}$ using water. DNA purification was performed using a Qiaquick Qiagen PCR purification Kit (Qiagen, Hilden, Germany) according to the manufacturer's instructions. The DNA was stored at $-20{ }^{\circ} \mathrm{C}$. Purified DNA from ChIP performed with empty vector strain was included as a background control.

Sequencing of ChIP samples was performed in the Laboratory of DNA Sequencing and Oligonucleotides Synthesis of Institute of Biochemistry and Biophysics Polish Academy of Sciences in Warsaw, Poland. NGS libraries were constructed using a QiaSeq Ultralow Input Library kit (Qiagen, Hilden, Germany). Samples were quality checked on 1\% agarose gel, and concentration was measured using a qPCR KAPA Library Quantification Kit (Roche Holding AG, Basel, Switzerland). Libraries were sequenced using standard Illumina protocols.

Reads were quality-checked and filtered using FASTP version 0.20.0 [78]. Reads were mapped to the P. aeruginosa PAO11161 genome (CP032126.1) using Bowtie2 version 2.3.4.3 [79] using default settings. Obtained *.sam files were sorted (samtools sort $-n$ ), run through samtools fixmate with the -m option, again sorted (samtools sort), and duplicates were marked with samtools markdup. Samtools ver. 1.9 was used [85]. The files were indexed and used to generate coverage *.bigwig files, which were normalized to $1 \times$ sequencing depth (RPGC), without binning and smoothing, using the bamCoverage tool ver 3.3.0, included in deepTools [86]. ChIP-seq peaks were called for merged ChIP replicates using MACS2 ver 2.1.2 [87] with default options for paired-end BAM files and 0.05 as the false discovery rate (FDR) adjusted p-value cut off. Peaks annotation and visualization of the coverage data were performed using custom R scripts. Raw data are available in the NCBI's Gene Expression Omnibus (GEO) database (http: / / www.ncbi.nlm.nih.gov /geo/; accessed on 20 February 2021) under accession number GSE167146.

\subsection{Construction of Promotor-lacZ Transcriptional Fusions and Promoter Activity Testing}

To test promoter activity in E. coli and P. aeruginosa, an RK2 derivative, the pCM132 plasmid with a promoterless lacZ reporter gene was used [51]. To construct pCM132 derivatives carrying PA3458p-lacZ and PA3459p-lacZ, DNA fragments were amplified by PCR using \#17/18\# or 19\#/20\# primer pairs, respectively, and digested with EcoRI, BamHI to ligate with EcoRI, BglII cut vector to obtain pKKB2.31 (PA3458p-lacZ) and pKKB2.32 (PA3459p-lacZ).

E. coli $\mathrm{DH} 5 \alpha \Delta$ lac was transformed with pairs of plasmids: pCM132m/pKGB8 (empty vectors as a control); pCM132m/pKKB2.11 (araBADp-PA3458); pKKB2.31 (PA3458p-lacZ)/ pKKB2.11; pKKB2.31/pKGB8; pKKB2.32 (PA3459p-lacZ)/pKKB2.11; pKKB2.32/pKGB8. The $\beta$-galactosidase activity was tested in extracts from stationary cells conducted without and with $0.02 \%$ arabinose at $37^{\circ} \mathrm{C}$ in LB containing kanamycin and chloramphenicol.

The $\beta$-galactosidase activity was also tested in extracts from PAO1161 WT and $\triangle P A 3458$ mutant carrying the empty vector (pCM132m), PA3458p-lacZ (pKKB2.31) or PA3459p-lacZ (pKKB2.32) grown at $37^{\circ} \mathrm{C}$ in LB containing kanamycin. 


\subsection{Bioinformatic Analysis}

A comparison of the HTH domain of chosen MarR-type regulators was performed using Clustal Omega [39]. Initial model of homodimer was generated by SWISS-MODEL [40]. DNA docking was performed in HDOCK SERVER [41]. Snapshots of a model were taken in UCSF Chimera software [88]. The DNA binding motifs were identified using MEMEChIP version 5.3.0 [50] using 200 bp around 319 or 9 PA3458 peak summits (Table S4). Clustered orthologs of PA3458-PA3461 were identified in 1748 reference genomes from Refseq database (Release 91) using MultiGeneBlast [53]. The -35/-10 boxes of promoter sequences were predicted using BPROM [89].

\section{Conclusions}

The PA3458 is the representative of the MarR-type regulators, which are involved in gene expression control in P. aeruginosa. Many binding sites of the protein were identified in P. aeruginosa genome, predisposing PA3458 to play a role as the global regulator, with one of the direct targets engaged in the production of bacterial osmoprotectant NAGGN. The transcriptional profiling showed relatively high expression of PA3458 in P. aeruginosa cells, except the late stationary phase, with the highest mRNA level detected in cells from the late logarithmic phase of growth. The activity of PA3458 and its target genes may play a role in the adaptation of bacterial cells to changing growth conditions, including osmotic stress. This is especially important in the light of infections caused by P. aeruginosa and changeable conditions prevailing during infection.

Supplementary Materials: The following are available online at https:/ /www.mdpi.com/article/ 10.3390/ijms22083982/s1: Table S1: Results of RNA-seq analysis of PA3458+ vs. EV+ P. aeruginosa PAO1161 cells. List of genes with altered expression identified by comparison of transcriptomes of cells overproducing PA3458 with transcriptomes of cells carrying the empty vector (fold change (FC) $\leq-2$ or $\geq 2$, FDR adjusted $p$-value $\leq 0.05$ ). Genes annotated only in PAO1161 strain but not in PAO1 are described as "not annotated". Table S2: Results of ChIP-seq analysis. The table represents data for PA3458-FLAG ChIP-seq peaks identified in each ChIP repeat without peaks found in negative control, as identified by MACS2 analysis. FDR-adjusted p-value for all peaks was lower than 0.05. Table S3: Results of ChIP-seq analysis with cut-off FE $>5$ ( 319 peaks). The table represents data for PA3458-FLAG ChIP-seq peaks identified in each ChIP repeat without peaks found in negative control, as identified by MACS2 analysis. FDR-adjusted p-value for all peaks was lower than 0.05. Motifs identified in summits of 306 ChIP-seq peaks, used to construct the logo of PA3458 binding site (motif A and A'-bolded). The PA3458 binding sequence motifs were identified using MEME-ChIP version 5.3.0 [49,50]. Table S4: Sequences of ChIP-seq peak summits with FE $>5$. In gray are marked sequences used to search PA3458 binding motif A'. Table S5. Distribution and evolutionary conservation of PA3458-PA3461 cluster in bacteria identified using MultiGeneBlast [53].

Author Contributions: Conceptualization, A.A.B.; methodology, K.K. (Karolina Kotecka)., A.K., K.K. (Kamil Kobylecki)., A.A.B.; software, A.K., K.K. (Karolina Kotecka)., K.K. (Kamil Kobylecki).; validation, K.K. (Karolina Kotecka)., A.K. and A.A.B.; formal analysis, K.K. (Karolina Kotecka)., A.K., A.A.B.; investigation, K.K. (Karolina Kotecka)., A.K., K.K. (Kamil Kobylecki)., A.A.B.; resources, K.K. (Karolina Kotecka)., A.K., K.K. (Kamil Kobylecki)., A.A.B.; data curation, K.K. (Karolina Kotecka)., A.K., K.K. (Kamil Kobylecki)., A.A.B.; writing—original draft preparation, K.K. (Karolina Kotecka)., A.K., A.A.B.; writing-review and editing, K.K. (Karolina Kotecka)., A.K., A.A.B.; visualization, K.K. (Karolina Kotecka)., A.K., K.K. (Kamil Kobylecki)., A.A.B.; supervision, A.A.B.; project administration, A.A.B.; funding acquisition, A.A.B. All authors have read and agreed to the published version of the manuscript. Please turn to the CRediT taxonomy for the term explanation. Authorship must be limited to those who have contributed substantially to the work reported.

Funding: This research was supported by the National Science Centre in Poland (grant 2015/18/E/ NZ2/00675).

Institutional Review Board Statement: Not applicable.

Informed Consent Statement: Not applicable. 
Data Availability Statement: Raw data of RNA-seq and ChIP-seq are available in the NCBI's Gene Expression Omnibus (GEO) database (http:/ / www.ncbi.nlm.nih.gov/geo/, accessed on 20 February 2021) under accession numbers GSE167147 and GSE167146, respectively.

Acknowledgments: We thank Jan Gawor, Karolina Zuchniewicz and Robert Gromadka (Laboratory of DNA Sequencing and Oligonucleotides Synthesis, IBB PAS, Warsaw, Poland) for help in performing DNA sequencing. We thank the Staff of Genomed S.A. (Poland) for performing RNA sequencing. This work was supported by the National Science Centre in Poland (grant 2015/18/E/NZ2/00675).

Conflicts of Interest: The authors declare no conflict of interest.

\section{Appendix A}
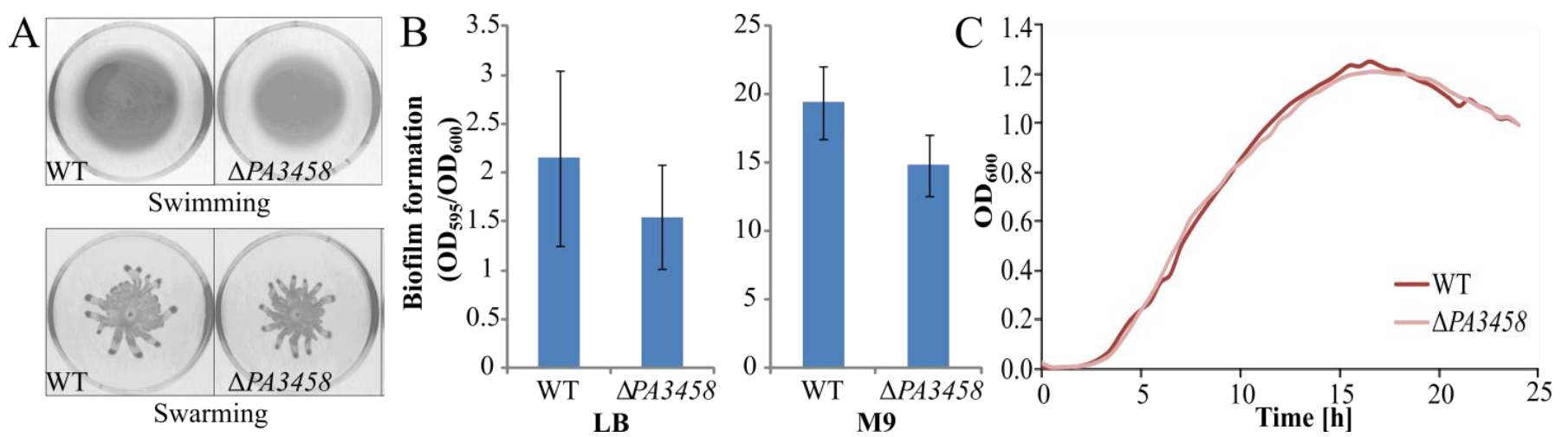

Figure A1. Phenotypic characterisation of PAO1161 $\triangle P A 3458$ deletion mutant. (A) Growth of PAO1161 and $\triangle P A 3458$ mutant on swimming and swarming medium. (B) Biofilm formation of PAO1161 leu ${ }^{-}$and $\triangle P A 3458$ mutant on LB or minimal medium with citrate. Data represent mean from five independent replicates. (C) Growth of PAO1161 and $\triangle P A 3458$ mutant on LB.
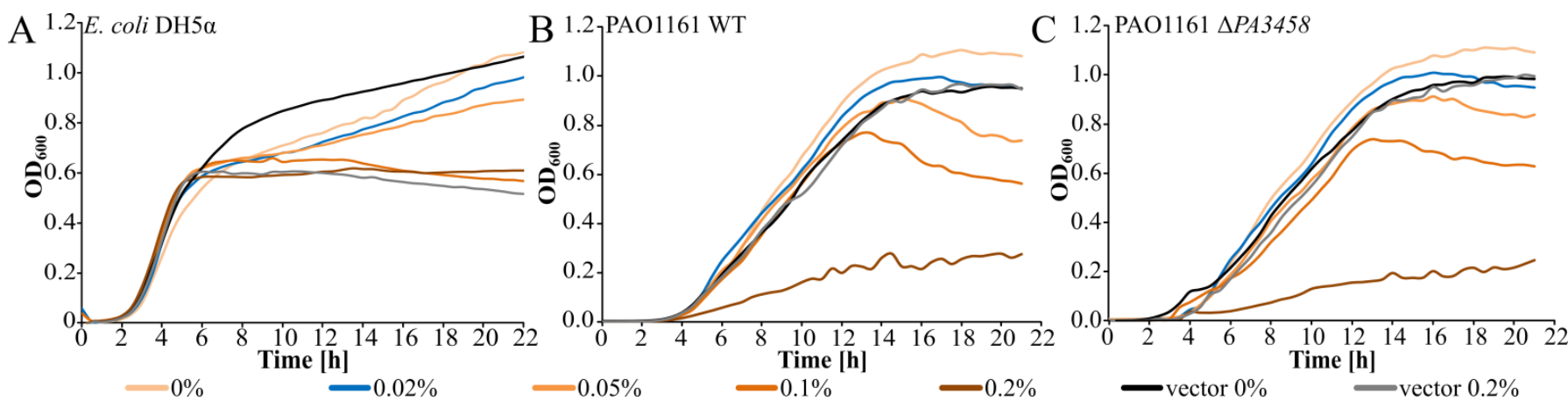

Figure A2. Effect of PA3458-FLAG overproduction on kinetics of growth. E. coli DH5 $\alpha$ (A), or P. aeruginosa PAO1161 (B) or $\triangle P A 3458(\mathbf{C})$ mutant strains carrying empty vector pABB28.3 araBADp-flag or pKKB2.11 araBADp-PA3458-flag were grown in LB under selection with the indicated concentration of inducer arabinose ( 0 to $0.2 \%)$. The blue line indicates the growth in the presence of $0.02 \%$ arabinose, which are conditions selected for ChIP-seq analysis. Data represent mean $\mathrm{OD}_{600}$ from three independent replicates. Standard deviations are not shown for clarity. 
A

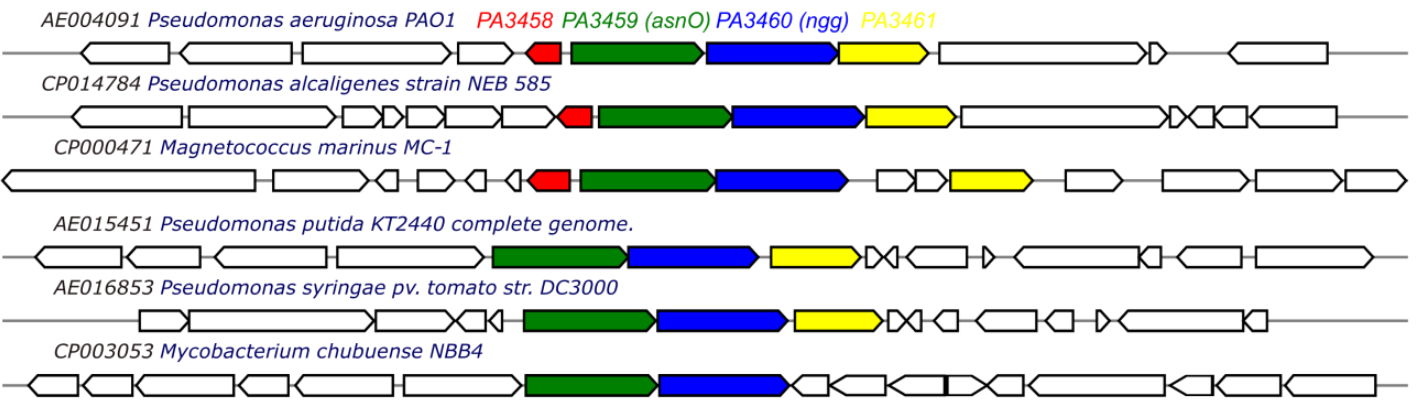

B

transcriptional regulator, TrmB [Magnetococcus marinus $\mathrm{MC}-1]$

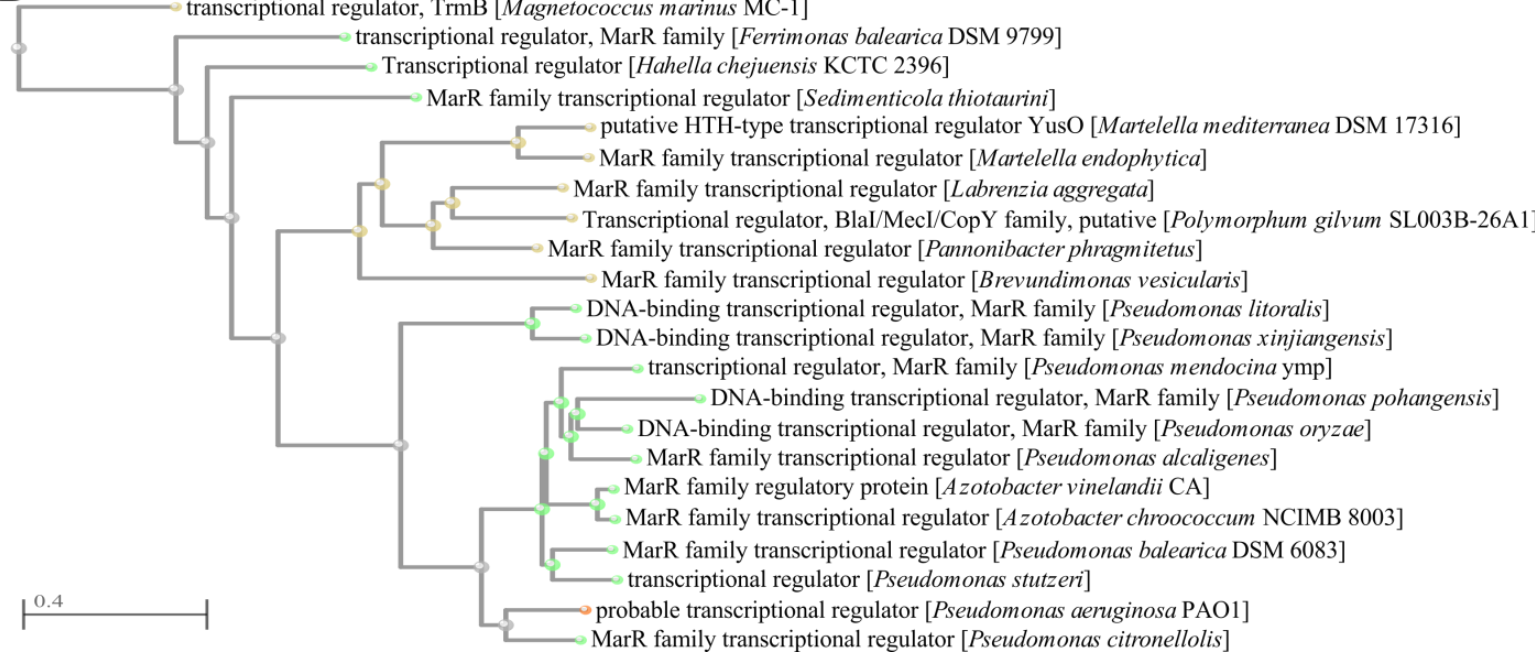

Figure A3. The occurrence of PA3458-PA3461 gene cluster in bacteria. (A) MultiGeneBlast comparison [53] of clustered orthologs of $P A 3458-P A 3461$ in representative and reference bacterial genomes included in the RefSeq database (release 91) [29]. Overall, 21 gene clusters were identified, and only selected results are presented (see also Table S5). (B) Phylogenetic tree of PA3458 orthologs constructed using CoBaltDB [90].

Table A1. Strains and vectors used in this study.

\begin{tabular}{|c|c|c|}
\hline \multicolumn{3}{|c|}{ E. coli Strains } \\
\hline $\mathrm{DH} 5 \alpha$ & $\begin{array}{c}\mathrm{F}^{-}(\varphi 80 \mathrm{~d} l a c Z \Delta \mathrm{M} 15) \text { recA1 endA1 gyrA96 thi-1 hsdR17 }\left(\mathrm{r}_{\mathrm{k}}{ }^{-} \mathrm{m}_{\mathrm{k}}{ }^{+}\right) \text {supE44 relA1 } \\
\text { deoR } \Delta(\text { lacZYA-argF }) U 196\end{array}$ & [91] \\
\hline BL21 & $\mathrm{F}^{-}$ompT hsdS $S_{\mathrm{B}}\left(\mathrm{r}_{\mathrm{b}}{ }^{-} \mathrm{m}_{\mathrm{b}}{ }^{-}\right) g a l d c m(\lambda \mathrm{DE} 3)$ & [91] \\
\hline S17-1 & pro hsdR hsdM recA $\mathrm{Tp}^{\mathrm{R}} \mathrm{Sm}^{\mathrm{R}} \Omega \mathrm{RP} 4-\mathrm{Tc}:$ : Mu-Km: : Tn7 & [91] \\
\hline $\mathrm{DH} 5 \alpha \Delta \mathrm{lac}$ & $\begin{array}{l}\text { F- (80dlacZM15), recA1, en-dA1, gyrA96, thi-1, hsdR17 (rk-mk+), supE44, relA1, } \\
\text { deoR } \Delta \text { (lacZYA-argF), U196 }\end{array}$ & lab collection \\
\hline \multicolumn{3}{|c|}{ Pseudomonas aeruginosaStrains } \\
\hline PAO1161 leu ${ }^{-}$ & $\mathrm{leu}^{-} \mathrm{r}^{-} \mathrm{m}^{+} \mathrm{Rif}^{\mathrm{R}}$ & [38] \\
\hline $\begin{array}{l}\text { PAO1161 leu } \\
\quad \triangle P A 3458\end{array}$ & deletion of $462 \mathrm{bp}$ fragment encompassing $P A 3458$ gene & this work \\
\hline $\begin{array}{l}\text { PAO1161 leu } \\
\quad \triangle P A 3459\end{array}$ & deletion of $1758 \mathrm{bp}$ fragment encompassing $P A 3459$ gene & this work \\
\hline $\begin{array}{l}\text { PAO1161 leu } \\
\triangle P A 3459-P A 3461\end{array}$ & deletion of $4749 \mathrm{bp}$ fragment encompassing $P A 3459-P A 3461$ putative operon & this work \\
\hline PAO1161 $\mathrm{leu}^{+}$ & $\mathrm{r}^{-} \mathrm{m}^{+} \operatorname{Rif}^{\mathrm{R}}$ & [48] \\
\hline $\begin{array}{l}\text { PAO1161 leu } \\
\quad \triangle P A 3458\end{array}$ & deletion of $462 \mathrm{bp}$ fragment encompassing $P A 3458$ gene & this work \\
\hline $\begin{array}{l}\text { PAO1161 leu } \\
\quad \triangle P A 3459\end{array}$ & deletion of $1758 \mathrm{bp}$ fragment encompassing $P A 3459$ gene & this work \\
\hline $\begin{array}{c}\text { PAO1161 leu+ } \\
\triangle P A 3459-P A 3461\end{array}$ & deletion of $4749 \mathrm{bp}$ fragment encompassing $P A 3459-P A 3461$ putative operon & this work \\
\hline
\end{tabular}


Table A1. Cont.

\begin{tabular}{|c|c|c|}
\hline \multicolumn{3}{|c|}{ Plasmids } \\
\hline pAKE600 & $\mathrm{Ap}^{\mathrm{r}} ;$ ori $_{\mathrm{MB} 1}$ ori $_{\mathrm{RK} 2}, \mathrm{sacB}$ & [77] \\
\hline pKKB2.61 & $\begin{array}{c}\text { Ap }{ }^{\mathrm{r}} \text {; pAKE600 derivative with } 437 \text { bp fragment encompassing up- and } \\
\text { down-sequence of PA3458, amplified using } 1 \# / 2 \# \text { and } 3 \# / 4 \# \text { primers and } \\
\text { cloned using BamHI, HindIII/HindIII, EcoRI }\end{array}$ & this work \\
\hline pKKB2.62 & $\begin{array}{c}\text { pAKE600 derivative with } 530 \text { bp fragment encompassing up- and } \\
\text { down-sequence of PA3459, amplified using 5\#/6\# and 7\#/8\# primers and } \\
\text { cloned using BamHI, HindIII/HindIII, EcoRI }\end{array}$ & this work \\
\hline pKKB2.63 & $\begin{array}{c}\text { pAKE600 derivative with } 541 \text { bp fragment encompassing up- and } \\
\text { down-sequence of PA3459-PA3461, amplified using 5\#/6\# and 9\#/10\# primers } \\
\text { and cloned using BamHI, HindIII/HindIII, EcoRI }\end{array}$ & this work \\
\hline pET28a $(+)$ & $\mathrm{Km}^{\mathrm{r}}$; ori $\mathrm{pBR} 322 ;$ ori $\mathrm{f} 1 ;$ expression vector & Novagen \\
\hline pKKB2.21 & $\begin{array}{c}\text { pET28a (+) derivative with } 513 \text { bp fragment, encoding } \text { His }_{6}-\mathrm{PA} 3458 \text {, amplified } \\
\text { using } 11 \# / 12 \# \text { primers and cloned using EcoRI, SacI }\end{array}$ & this work \\
\hline pKKB2.22 & $\begin{array}{c}\text { pET28a (+) derivative with } 483 \text { bp fragment, encoding PA3458-His } 6 \text {, amplified } \\
\text { using 13\#/14\# primers and cloned using NcoI, HindIII }\end{array}$ & this work \\
\hline pKGB8 & $\mathrm{Cm}^{\mathrm{r}}$; IncA/C broad-host-range cloning vector, mob, araC- $p B A D p$ & [46] \\
\hline pABB28.3 & pKGB8 derivative with flag & this work \\
\hline pKKB2.11 & $\begin{array}{c}\text { pKGB8 derivative with } 513 \text { bp fragment, encoding PA3458, amplified using } \\
\text { 11\#/12\# primers and cloned using EcoRI, SacI }\end{array}$ & this work \\
\hline pКАВ20B & Ap $^{r}$; pUC19 derivative with $\mathrm{His}_{6}$-mcs (MunI, HindIII, NotI, XhoI, BamHI)-flag & this work \\
\hline pKKB2.91 & $\begin{array}{l}\text { pKAB20B derivative with } 483 \text { bp fragment, encoding PA3458-FLAG, } \\
\text { amplified using 11\#/15\# primers and cloned using NcoI, BamHI }\end{array}$ & this work \\
\hline pKKB2.12 & $\begin{array}{l}\text { pKGB8 derivative with } 618 \mathrm{bp} \text { fragment encoding PA3458-FLAG cloned using } \\
\text { EcoRI, SalI cut from pKKB2.91 }\end{array}$ & this work \\
\hline pCM132 & $\mathrm{Km}^{\mathrm{r}} ;$ ori $V_{\mathrm{RK} 2} ;$ ori $T_{\mathrm{RK} 2} ;$ promoter less lac $Z$ reporter gene & [51] \\
\hline pKKB2.31 & $\begin{array}{l}\text { pCM132 derivative with } 281 \text { bp fragment amplified with primers } 17 \# / 18 \# \text {, } \\
\text { cloned using EcoRI, BamHI/BglII encompassing PA3458 promoter }(P A 3458 \mathrm{p})\end{array}$ & this work \\
\hline pKKB2.32 & $\begin{array}{l}\text { pCM132 derivative with } 266 \text { bp fragment amplified with primers } 19 \# / 20 \# \text {, } \\
\text { cloned using EcoRI, BamHI/BglII encompassing PA3459 promoter (PA3459p) }\end{array}$ & this work \\
\hline
\end{tabular}

Table A2. Primers used in this study.

\begin{tabular}{|c|c|c|c|}
\hline $\mathrm{Nr}$ & Starter Name & Use & Seqence \\
\hline$\# 1$ & $3458 \mathrm{mLF}$ & \multirow{4}{*}{ PA3458 gene deletion } & gcggatccACGAAACTCTCCTGATATG (BamHI) \\
\hline$\# 2$ & 3458mLR & & gcaagcTTACTTTCAACCATAATAAATTCTTC (HindIII) \\
\hline$\# 3$ & $3458 \mathrm{mPF}$ & & gcaagctttaatAGTGAGGGCGCCAGGTTCG (HindIII) \\
\hline$\# 4$ & $3458 \mathrm{mPR}$ & & gcgaattCAACGCCTGTTCGCGCTGATGCTG (EcoRI) \\
\hline$\# 5$ & 3459-61mLF & \multirow{2}{*}{$\begin{array}{l}\text { PA3459 gene and } P A 3459-61 \\
\text { operon deletion }\end{array}$} & gcggatccAGACGCTTGGAGTGGATTTC (BamHI) \\
\hline \#6 & 3459-61mLR & & gcaagcttGCCGCACATATTCCTTACC(HindIII) \\
\hline \#7 & $3459 \mathrm{mPF}$ & \multirow{2}{*}{ PA3459 gene deletion } & gcaagctttaatagTGAAAATGGGCCCCCAACGC(HindIII) \\
\hline \#8 & $3459 \mathrm{mPR}$ & & gcgaattcACAGGTCGCGGGCCAATTCC (EcoRI) \\
\hline \#9 & 3459-61mLF & \multirow{2}{*}{ PA3459-61 operon deletion } & gcaagctttagtaaTGAGCCCGCGCCGGCCT (HindIII) \\
\hline$\# 10$ & 3459-61mLR & & gcgaattcGTACTCGGCGTATGCGCCCAGG (EcoRI) \\
\hline$\# 11$ & $3458 \mathrm{eF}$ & \multirow{5}{*}{ PA3458 expression } & gcgaattcATGGTTGAAAGTAATAAGACCG (EcoRI) \\
\hline$\# 12$ & $3458 \mathrm{eR}$ & & gcgagctcCTGTCTTTCGTAGCGAAC (SacI) \\
\hline \#13 & $3458 \mathrm{eF} 3$ & & cgccatggATGGTTGAAAGTAATAAGACCGCTGC (NcoI) \\
\hline$\# 14$ & $3458 \mathrm{e} 3$ & & gcaagcttCTCTTCTTCGACGTCCTCTTCC (HindIII) \\
\hline \#15 & $3458 \mathrm{eR} 4$ & & gcggatccCTCTTCTTCGACGTCCTCTTCC (BamHI) \\
\hline
\end{tabular}


Table A2. Cont.

\begin{tabular}{|c|c|c|c|}
\hline $\mathrm{Nr}$ & Starter Name & Use & Seqence \\
\hline$\# 16$ & $3458 \mathrm{pF}$ & \multirow{2}{*}{$\begin{array}{c}\text { PA3458 } \\
\text { promoter cloning }\end{array}$} & cagaattcgcatgcCCAGGTCCATGATCTTCAGC (EcoRI/SphI) \\
\hline$\# 17$ & $3458 \mathrm{pR}$ & & gcggatccATAAATTCTTCGTTAAGGGTCCTGATAG (BamHI) \\
\hline \#18 & $3459 \mathrm{pF}$ & \multirow{2}{*}{$\begin{array}{c}\text { PA3459 } \\
\text { promoter cloning }\end{array}$} & cagaattcgcatgcCGTATCGGCTGAGACGCTTG (EcoRI/SphI) \\
\hline \#19 & $3459 \mathrm{pR}$ & & gcggatccATTCCTTACCGGTTCTCCGTTG (BamHI) \\
\hline \#20 & $\operatorname{nadBqF}$ & \multirow{36}{*}{ RT-qPCR } & CTACCTGGACATCAGCCACA \\
\hline \#21 & nadBqR & & GGTAATGTCGATGCCGAAGT \\
\hline \#22 & proCqF & & CAGGCCGGGCAGTTGCTGTC \\
\hline \#23 & proCqR & & GGTCAGGCGCGAGGCTGTCT \\
\hline \#24 & $3458 \mathrm{qF}$ & & TAATAAGACCGCTGCCGATACC \\
\hline$\# 25$ & $3458 \mathrm{qR}$ & & TGAGACGCTTGGAGTGGATTTC \\
\hline \#26 & $3459 \mathrm{qF}$ & & CCCGGCTCAATGGGATGTTC \\
\hline$\# 27$ & $3459 \mathrm{qR}$ & & AGCGGTCGAGGCTGTAGTAG \\
\hline \#28 & $3973 q F$ & & GGATCCTGAAGTCGACGAGC \\
\hline \#29 & $3973 q R$ & & GAAAGCTGGAATGCGCCAC \\
\hline$\# 30$ & $2204 \mathrm{qF}$ & & CAGGTGGACTTCAGCATCCC \\
\hline$\# 31$ & 2204qR & & CGCCACTTGTTGAGGACTTC \\
\hline \#32 & $2252 q F$ & & GGGTGCCTACTTCACGATCC \\
\hline$\# 33$ & $2252 q R$ & & ATCAGGGCCTGGAAGGAACT \\
\hline \#34 & $2264 \mathrm{qF}$ & & CTACCAGCCTCGCTTCTTCA \\
\hline$\# 35$ & $2264 q R$ & & CTGTCGGTCGATGAACTCCG \\
\hline \#36 & $2776 \mathrm{qF}$ & & ACGGTATCCAATGCGACCTG \\
\hline \#37 & $2776 q R$ & & GGCGTCCATGATCTCCAACT \\
\hline$\# 38$ & $3356 \mathrm{qF}$ & & GGGCGAAACATCTTCAGCGA \\
\hline$\# 39$ & 3356qR & & GCTGGAAGGAGTTCACATGC \\
\hline$\# 40$ & 3923qF & & CTACTGCGAGAACGATGGCT \\
\hline \#41 & $3923 q R$ & & ACACTGGGCTTGAGGTTCAC \\
\hline$\# 42$ & $4296 \mathrm{qF}$ & & CTACCGTTGCGTAACCAGCA \\
\hline$\# 43$ & $4296 \mathrm{qR}$ & & GCTCTCGATCAGGCGGATAC \\
\hline$\# 44$ & $4352 q F$ & & ATGAAACGAATCCTGGTGGC \\
\hline \#45 & $4352 q R$ & & CACGTTCAGCACGGTCAGTT \\
\hline$\# 46$ & $5099 \mathrm{qF}$ & & GACGTATAGCCGTAGTGGGC \\
\hline$\# 47$ & $5099 \mathrm{qR}$ & & GTGCTATCCGGACGATCCAC \\
\hline$\# 48$ & $5100 \mathrm{qF}$ & & GTGATCGTCTGCGACGGTAG \\
\hline \#49 & $5100 \mathrm{qR}$ & & CAATCGATGGCGACCTGGTA \\
\hline$\# 50$ & $5170 \mathrm{qF}$ & & ТСТTCТСССТСССGCAAAAC \\
\hline$\# 51$ & 5170qR & & AAGACGAAAGCGAGGGTGAG \\
\hline$\# 52$ & $1270 \mathrm{qF}$ & & CTATAGCGGCATGGTCCTGG \\
\hline$\# 53$ & $1270 \mathrm{qR}$ & & GATGCCTGGCCATAGAGTGC \\
\hline$\# 54$ & $3461 \mathrm{qF}$ & & CGGACCTCAACTACCTGCAA \\
\hline \#55 & 3461qR & & CGCACGATGGTATCGGTGAA \\
\hline
\end{tabular}




\section{References}

1. Gellatly, S.L.; Hancock, R.E.W. Pseudomonas aeruginosa: New insights into pathogenesis and host defenses. Pathog. Dis. 2013, 67, 159-173. [CrossRef] [PubMed]

2. Palser, S.; Smith, S.; Nash, E.F.; Agarwal, A.; Smyth, A.R. Treatments for preventing recurrence of infection with Pseudomonas aeruginosa in people with cystic fibrosis. Cochrane Database Syst. Rev. 2019, 12, CD012300. [CrossRef]

3. Azam, M.W.; Khan, A.U. Updates on the pathogenicity status of Pseudomonas aeruginosa. Drug Discov. Today 2019, 24, 350-359. [CrossRef] [PubMed]

4. Poole, K. Stress responses as determinants of antimicrobial resistance in Pseudomonas aeruginosa: Multidrug efflux and more. Can. J. Microbiol. 2014, 60, 783-791. [CrossRef] [PubMed]

5. Moradali, M.F.; Ghods, S.; Rehm, B.H.A. Pseudomonas aeruginosa lifestyle: A paradigm for adaptation, survival, and persistence. Front. Cell Infect. Microbiol. 2017, 7, 39. [CrossRef]

6. Allan, B.; Linseman, M.; MacDonald, L.A.; Lam, J.S.; Kropinski, A.M. Heat shock response of Pseudomonas aeruginosa. J. Bacteriol. 1988, 170, 3668-3674. [CrossRef] [PubMed]

7. Morita, Y.; Tomida, J.; Kawamura, Y. Responses of Pseudomonas aeruginosa to antimicrobials. Front. Microbiol. $2014,4,422$. [CrossRef]

8. Rezaie, P.; Pourhajibagher, M.; Chiniforush, N.; Hosseini, N.; Bahador, A. The effect of quorum-sensing and efflux pumps interactions in Pseudomonas aeruginosa against photooxidative stress. J. Lasers Med. Sci. 2018, 9, 161-167. [CrossRef]

9. Aspedon, A.; Palmer, K.; Whiteley, M. Microarray analysis of the osmotic stress response in Pseudomonas aeruginosa. J. Bacteriol. 2006, 188, 2721-2725. [CrossRef]

10. Kim, S.; Ha, J.; Lee, H.; Lee, S.; Lee, J.; Choi, Y.; Oh, H.; Yoon, Y.; Choi, K.-H. Role of Pseudomonas aeruginosa DesB in adaptation to osmotic stress. J. Food Prot. 2019, 82, 1278-1282. [CrossRef]

11. Stover, C.K.; Pham, X.Q.; Erwin, A.L.; Mizoguchi, S.D.; Warrener, P.; Hickey, M.J.; Brinkman, F.S.; Hufnagle, W.O.; Kowalik, D.J.; Lagrou, M.; et al. Complete genome sequence of Pseudomonas aeruginosa PAO1, an opportunistic pathogen. Nature 2000, 406, 959-964. [CrossRef]

12. Perez-Rueda, E.; Hernandez-Guerrero, R.; Martinez-Nuñez, M.A.; Armenta-Medina, D.; Sanchez, I.; Ibarra, J.A. Abundance, diversity and domain architecture variability in prokaryotic DNA-binding transcription factors. PLoS ONE 2018, 13, e0195332. [CrossRef]

13. Grove, A. MarR family transcription factors. Curr. Biol. 2013, 23, R142-R143. [CrossRef] [PubMed]

14. Alekshun, M.N.; Levy, S.B.; Mealy, T.R.; Seaton, B.A.; Head, J.F. The crystal structure of MarR, a regulator of multiple antibiotic resistance, at $2.3 \AA$ A resolution. Nat. Struct. Biol. 2001, 8, 710-714. [CrossRef] [PubMed]

15. Alekshun, M.N.; Levy, S.B. Regulation of chromosomally mediated multiple antibiotic resistance: The Mar regulon. Antimicrob. Agents Chemother. 1997, 41, 2067-2075. [CrossRef]

16. Martin, R.G.; Rosner, J.L. Binding of purified multiple antibiotic-resistance repressor protein (MarR) to Mar operator sequences. Proc. Natl. Acad. Sci. USA 1995, 92, 5456-5460. [CrossRef]

17. Barbosa, T.M.; Levy, S.B. Differential expression of over 60 chromosomal genes in Escherichia coli by constitutive expression of MarA. J. Bacteriol. 2000, 182, 3467-3474. [CrossRef] [PubMed]

18. Martin, R.G.; Jair, K.W.; Wolf, R.E.; Rosner, J.L. Autoactivation of the MarRAB multiple antibiotic resistance operon by the MarA transcriptional activator in Escherichia coli. J. Bacteriol. 1996, 178, 2216-2223. [CrossRef]

19. Deochand, D.K.; Grove, A. MarR family transcription factors: Dynamic variations on a common scaffold. Crit. Rev. Biochem. Mol. Biol. 2017, 52, 595-613. [CrossRef]

20. Wei, K.; Tang, D.-J.; He, Y.-Q.; Feng, J.-X.; Jiang, B.-L.; Lu, G.-T.; Chen, B.; Tang, J.-L. HpaR, a putative MarR family transcriptional regulator, is positively controlled by HrpG and HrpX and involved in the pathogenesis, hypersensitive response, and extracellular protease production of Xanthomonas cmpestris pathovar campestris. J. Bacteriol. 2007, 189, 2055-2062. [CrossRef]

21. Zhang, Y.; Luo, F.; Wu, D.; Hikichi, Y.; Kiba, A.; Igarashi, Y.; Ding, W.; Ohnishi, K. PrhN, a putative MarR family transcriptional regulator, is involved in positive regulation of Type III Secretion System and full virulence of Ralstonia solanacearum. Front. Microbiol. 2015, 6. [CrossRef]

22. Haque, M.M.; Kabir, M.S.; Aini, L.Q.; Hirata, H.; Tsuyumu, S. SlyA, a MarR family transcriptional regulator, is essential for virulence in Dickeya dadantii 3937. J. Bacteriol. 2009, 191, 5409-5418. [CrossRef]

23. Michaux, C.; Sanguinetti, M.; Reffuveille, F.; Auffray, Y.; Posteraro, B.; Gilmore, M.S.; Hartke, A.; Giard, J.-C. SlyA is a transcriptional regulator involved in the virulence of Enterococcus faecalis. Infect. Immun. 2011, 79, 2638-2645. [CrossRef]

24. Michaux, C.; Martini, C.; Hanin, A.; Auffray, Y.; Hartke, A.; Giard, J.-C. SlyA Regulator is involved in bile salts stress response of Enterococcus faecalis. FEMS Microbiol. Lett. 2011, 324, 142-146. [CrossRef]

25. Buchmeier, N.; Bossie, S.; Chen, C.Y.; Fang, F.C.; Guiney, D.G.; Libby, S.J. SlyA, a transcriptional regulator of Salmonella typhimurium, is required for resistance to oxidative stress and is expressed in the intracellular environment of macrophages. Infect. Immun. 1997, 65, 3725-3730. [CrossRef] [PubMed]

26. Leelakriangsak, M.; Huyen, N.T.T.; Töwe, S.; Duy, N.V.; Becher, D.; Hecker, M.; Antelmann, H.; Zuber, P. Regulation of quinone detoxification by the thiol stress sensing DUF24/MarR-like repressor, YodB in Bacillus subtilis. Mol. Microbiol. 2008, 67, 1108-1124. [CrossRef] [PubMed] 
27. Si, M.; Chen, C.; Su, T.; Che, C.; Yao, S.; Liang, G.; Li, G.; Yang, G. CosR is an oxidative stress sensing a MarR-Type transcriptional repressor in Corynebacterium glutamicum. Biochem. J. 2018, 475, 3979-3995. [CrossRef] [PubMed]

28. Teixeira, F.L.; Silva, D.N.; Pauer, H.; Ferreira, L.Q.; Ferreira, E.; Domingues, R.M.; Lobo, L.A. The role of BmoR, a MarR family regulator, in the survival of Bacteroides fragilis during oxidative stress. Int. J. Med. Microbiol. 2013, 303, 443-448. [CrossRef]

29. O'Leary, N.A.; Wright, M.W.; Brister, J.R.; Ciufo, S.; Haddad, D.; McVeigh, R.; Rajput, B.; Robbertse, B.; Smith-White, B.; Ako-Adjei, D.; et al. Reference Sequence (RefSeq) database at NCBI: Current status, taxonomic expansion, and functional annotation. Nucleic Acids Res. 2016, 44, D733-D745. [CrossRef]

30. Winsor, G.L.; Lo, R.; Sui, S.J.H.; Ung, K.S.E.; Huang, S.; Cheng, D.; Ching, W.-K.H.; Hancock, R.E.W.; Brinkman, F.S.L. Pseudomonas aeruginosa genome database and PseudoCAP: Facilitating community-based, continually updated, genome annotation. Nucleic Acids Res. 2005, 33, D338-D343. [CrossRef]

31. Sánchez, P.; Rojo, F.; Martínez, J.L. Transcriptional regulation of MexR, the repressor of Pseudomonas aeruginosa MexAB-OprM multidrug efflux pump. FEMS Microbiol. Lett. 2002, 207, 63-68. [CrossRef]

32. Ziha-Zarifi, I.; Llanes, C.; Köhler, T.; Pechere, J.-C.; Plesiat, P. In Vivo emergence of multidrug-resistant mutants of Pseudomonas aeruginosa overexpressing the active efflux system MexA-MexB-OprM. Antimicrob. Agents Chemother. 1999, 43, 287-291. [CrossRef] [PubMed]

33. Chen, H.; Hu, J.; Chen, P.R.; Lan, L.; Li, Z.; Hicks, L.M.; Dinner, A.R.; He, C. The Pseudomonas aeruginosa multidrug efflux regulator MexR uses an oxidation-sensing mechanism. Proc. Natl. Acad. Sci. USA 2008, 105, 13586-13591. [CrossRef]

34. Atichartpongkul, S.; Vattanaviboon, P.; Wisitkamol, R.; Jaroensuk, J.; Mongkolsuk, S.; Fuangthong, M. Regulation of organic hydroperoxide stress response by two OhrR homologs in Pseudomonas aeruginosa. PLoS ONE 2016, 11, e0161982. [CrossRef] [PubMed]

35. Kim, S.-H.; Park, S.-Y.; Heo, Y.-J.; Cho, Y.-H. Drosophila melanogaster-based screening for multihost virulence factors of Pseudomonas aeruginosa PA14 and identification of a virulence-attenuating factor, HudA. Infect. Immun. 2008, 76, 4152-4162. [CrossRef] [PubMed]

36. Bartosik, A.A.; Glabski, K.; Jecz, P.; Mikulska, S.; Fogtman, A.; Koblowska, M.; Jagura-Burdzy, G. Transcriptional profiling of par $A$ and parB mutants in actively dividing cells of an opportunistic human pathogen Pseudomonas aeruginosa. PLoS ONE 2014, 9, e87276. [CrossRef] [PubMed]

37. Bartosik, A.A.; Mierzejewska, J.; Thomas, C.M.; Jagura-Burdzy, G. ParB deficiency in Pseudomonas aeruginosa destabilizes the partner protein ParA and affects a variety of physiological parameters. Microbiology 2009, 155, 1080-1092. [CrossRef] [PubMed]

38. Lasocki, K.; Bartosik, A.A.; Mierzejewska, J.; Thomas, C.M.; Jagura-Burdzy, G. Deletion of the ParA (Soj) homologue in Pseudomonas aeruginosa causes ParB instability and affects growth rate, chromosome segregation, and motility. J. Bacteriol. 2007, 189, 5762-5772. [CrossRef]

39. Madeira, F.; Park, Y.M.; Lee, J.; Buso, N.; Gur, T.; Madhusoodanan, N.; Basutkar, P.; Tivey, A.R.N.; Potter, S.C.; Finn, R.D.; et al. The EMBL-EBI search and sequence analysis tools APIs in 2019. Nucleic Acids Res. 2019, 47, W636-W641. [CrossRef]

40. Waterhouse, A.; Bertoni, M.; Bienert, S.; Studer, G.; Tauriello, G.; Gumienny, R.; Heer, F.T.; de Beer, T.A.P.; Rempfer, C.; Bordoli, L.; et al. SWISS-MODEL: Homology modelling of protein structures and complexes. Nucleic Acids Res. 2018, 46, W296-W303. [CrossRef] [PubMed]

41. Yan, Y.; Tao, H.; He, J.; Huang, S.-Y. The HDOCK Server for integrated protein-protein docking. Nat. Protoc. 2020, 15, 1829-1852. [CrossRef] [PubMed]

42. Yaron, S.; White, D.G.; Matthews, K.R. Characterization of an Escherichia coli O157:H7 MarR mutant. Int. J. Food Microbiol. 2003, 85, 281-291. [CrossRef]

43. Will, W.R.; Brzovic, P.; Le Trong, I.; Stenkamp, R.E.; Lawrenz, M.B.; Karlinsey, J.E.; Navarre, W.W.; Main-Hester, K.; Miller, V.L.; Libby, S.J.; et al. The evolution of SlyA/RovA transcription factors from repressors to countersilencers in Enterobacteriaceae. MBio 2019, 10. [CrossRef]

44. Davis, J.R.; Brown, B.L.; Page, R.; Sello, J.K. Study of PcaV from Streptomyces coelicolor yields new insights into ligand-responsive MarR family transcription factors. Nucleic Acids Res. 2013, 41, 3888-3900. [CrossRef] [PubMed]

45. Gao, Y.-R.; Li, D.-F.; Fleming, J.; Zhou, Y.-F.; Liu, Y.; Deng, J.-Y.; Zhou, L.; Zhou, J.; Zhu, G.-F.; Zhang, X.-E.; et al. Structural analysis of the regulatory mechanism of MarR protein Rv2887 in M. tuberculosis. Sci. Rep. 2017, 7, 6471. [CrossRef] [PubMed]

46. Kawalek, A.; Glabski, K.; Bartosik, A.A.; Fogtman, A.; Jagura-Burdzy, G. Increased ParB level affects expression of stress response, adaptation and virulence operons and potentiates repression of promoters adjacent to the high affinity binding sites ParS3 and ParS4 in Pseudomonas aeruginosa. PLoS ONE 2017, 12, e0181726. [CrossRef]

47. Kovach, M.E.; Phillips, R.W.; Elzer, P.H.; Roop, R.M.; Peterson, K.M. PBBR1MCS: A broad-host-range cloning vector. Biotechniques 1994, 16, 800-802. [PubMed]

48. Kawalek, A.; Kotecka, K.; Modrzejewska, M.; Gawor, J.; Jagura-Burdzy, G.; Bartosik, A.A. Genome sequence of Pseudomonas aeruginosa PAO1161, a PAO1 derivative with the ICEPae1161 integrative and conjugative element. BMC Genom. 2020, 21, 14. [CrossRef]

49. Bailey, T.L.; Boden, M.; Buske, F.A.; Frith, M.; Grant, C.E.; Clementi, L.; Ren, J.; Li, W.W.; Noble, W.S. MEME Suite: Tools for motif discovery and searching. Nucleic Acids Res. 2009, 37, W202-W208. [CrossRef]

50. Machanick, P.; Bailey, T.L. MEME-ChIP: Motif analysis of large DNA datasets. Bioinformatics 2011, 27, 1696-1697. [CrossRef] 
51. Marx, C.J.; Lidstrom, M.E. Development of improved versatile broad-host-range vectors for use in methylotrophs and other gram-negative bacteria. Microbiology 2001, 147, 2065-2075. [CrossRef]

52. Sagot, B.; Gaysinski, M.; Mehiri, M.; Guigonis, J.-M.; Rudulier, D.L.; Alloing, G. Osmotically induced synthesis of the dipeptide N-Acetylglutaminylglutamine amide is mediated by a new pathway conserved among bacteria. Proc. Natl. Acad. Sci. USA 2010, 107, 12652-12657. [CrossRef]

53. Medema, M.H.; Takano, E.; Breitling, R. Detecting sequence homology at the gene cluster level with MultiGeneBlast. Mol. Biol. Evol. 2013, 30, 1218-1223. [CrossRef]

54. Tümmler, B.; Wiehlmann, L.; Klockgether, J.; Cramer, N. Advances in understanding Pseudomonas. F1000Prime Rep. 2014, 6, 9. [CrossRef]

55. Will, W.R.; Fang, F.C. The evolution of MarR family transcription factors as counter-silencers in regulatory networks. Curr. Opin. Microbiol. 2020, 55, 1-8. [CrossRef] [PubMed]

56. D'Souza-Ault, M.R.; Smith, L.T.; Smith, G.M. Roles of N-acetylglutaminylglutamine amide and glycine betaine in adaptation of Pseudomonas aeruginosa to osmotic stress. Appl. Environ. Microbiol. 1993, 59, 473-478. [CrossRef] [PubMed]

57. Libby, S.J.; Goebel, W.; Ludwig, A.; Buchmeier, N.; Bowe, F.; Fang, F.C.; Guiney, D.G.; Songer, J.G.; Heffron, F. A Cytolysin encoded by Salmonella is required for survival within macrophages. Proc. Natl. Acad. Sci. USA 1994, 91, 489-493. [CrossRef] [PubMed]

58. Booth, I.R.; Higgins, C.F. Enteric bacteria and osmotic stress: Intracellular potassium glutamate as a secondary signal of osmotic stress? FEMS Microbiol. Rev. 1990, 6, 239-246. [CrossRef] [PubMed]

59. Dorman, C.J.; Dorman, M.J. DNA Supercoiling is a fundamental regulatory principle in the control of bacterial gene expression. Biophys. Rev. 2016, 8, 209-220. [CrossRef]

60. Dillon, S.C.; Dorman, C.J. Bacterial nucleoid-associated proteins, nucleoid structure and gene expression. Nat. Rev. Microbiol. 2010, 8, 185-195. [CrossRef]

61. Hünnefeld, M.; Persicke, M.; Kalinowski, J.; Frunzke, J. The MarR-Type Regulator MalR is involved in stress-responsive cell envelope remodeling in Corynebacterium glutamicum. Front. Microbiol. 2019, 10. [CrossRef]

62. Pan, Y.; Liang, F.; Li, R.-J.; Qian, W. MarR-family transcription factor HpaR controls expression of the VgrR-VgrS operon of Xanthomonas campestris pv. campestris. Mol. Plant Microbe Interact. 2017, 31, 299-310. [CrossRef] [PubMed]

63. Gregory, G.J.; Morreale, D.P.; Boyd, E.F. CosR is a global regulator of the osmotic stress response with widespread distribution among bacteria. Appl. Environ. Microbiol. 2020. [CrossRef]

64. Koskenkorva-Frank, T.S.; Kallio, P.T. Induction of Pseudomonas aeruginosa Fhp and FhpR by reactive oxygen Species. Can. J. Microbiol. 2009, 55, 657-663. [CrossRef]

65. Forrester, M.T.; Foster, M.W. Protection from nitrosative stress: A central role for microbial flavohemoglobin. Free Radic. Biol. Med. 2012, 52, 1620-1633. [CrossRef] [PubMed]

66. Firoved, A.M.; Wood, S.R.; Ornatowski, W.; Deretic, V.; Timmins, G.S. Microarray analysis and functional characterization of the nitrosative stress response in nonmucoid and mucoid Pseudomonas aeruginosa. J. Bacteriol. 2004, 186, 4046-4050. [CrossRef] [PubMed]

67. Zhang, Y.; Qin, J.; Tan, B.; Kong, W.; Chen, G.; Zhang, C.; Liang, H. The P-type ATPase PA1429 regulates quorum-sensing systems and bacterial virulence. Front. Microbiol. 2017, 8. [CrossRef]

68. Borriello, G.; Richards, L.; Ehrlich, G.D.; Stewart, P.S. Arginine or nitrate enhances antibiotic susceptibility of Pseudomonas aeruginosa in biofilms. Antimicrob. Agents Chemother. 2006, 50, 382-384. [CrossRef]

69. Lüthi, E.; Baur, H.; Gamper, M.; Brunner, F.; Villeval, D.; Mercenier, A.; Haas, D. The Arc operon for anaerobic arginine catabolism in Pseudomonas aeruginosa contains an additional gene, $\operatorname{arcD}$, encoding a membrane protein. Gene 1990, 87, 37-43. [CrossRef]

70. Benkert, B.; Quäck, N.; Schreiber, K.; Jaensch, L.; Jahn, D.; Schobert, M. Nitrate-responsive NarX-NarL represses arginine-mediated induction of the Pseudomonas aeruginosa arginine fermentation arcDABC operon. Microbiology 2008, 154, 3053-3060. [CrossRef]

71. Chou, H.T.; Li, J.-Y.; Peng, Y.-C.; Lu, C.-D. Molecular characterization of PauR and its role in control of putrescine and cadaverine catabolism through the $\gamma$-glutamylation pathway in Pseudomonas aeruginosa PAO1. J. Bacteriol. 2013, 195, 3906-3913. [CrossRef]

72. Koskenkorva, T.; Aro-Kärkkäinen, N.; Bachmann, D.; Arai, H.; Frey, A.D.; Kallio, P.T. Transcriptional activity of Pseudomonas aeruginosa fhp promoter is dependent on two regulators in addition to FhpR. Arch. Microbiol. 2008, 189, 385-396. [CrossRef]

73. Díaz-Pérez, A.L.; Núñez, C.; Meza Carmen, V.; Campos-García, J. The expression of the genes involved in leucine catabolism of Pseudomonas aeruginosa is controlled by the transcriptional regulator LiuR and by the CbrAB/Crc system. Res. Microbiol. 2018, 169, 324-334. [CrossRef] [PubMed]

74. Boes, N.; Schreiber, K.; Härtig, E.; Jaensch, L.; Schobert, M. The Pseudomonas aeruginosa universal stress protein PA4352 is essential for surviving anaerobic energy stress. J. Bacteriol. 2006, 188, 6529-6538. [CrossRef] [PubMed]

75. Kahn, M.; Kolter, R.; Thomas, C.; Figurski, D.; Meyer, R.; Remaut, E.; Helinski, D.R. Plasmid Cloning Vehicles Derived from Plasmids ColE1, F, R6K, and RK2. Methods Enzymol. 1979, 68, 268-280. [CrossRef] [PubMed]

76. Sambrook, J.; Maniatis, T.; Fritsch, E.F.; Laboratory, C.S.H. Molecular Cloning: A Laboratory Manual, 2nd ed.; Cold Spring Harbor Laboratory Press: Cold Spring Harbor, NY, USA, 1987; ISBN 978-0-87969-309-1.

77. El-Sayed, A.K.; Hothersall, J.; Thomas, C.M. Quorum-sensing-dependent regulation of biosynthesis of the polyketide antibiotic mupirocin in Pseudomonas fluorescens NCIMB 10586. Microbiology 2001, 147, 2127-2139. [CrossRef] [PubMed]

78. Chen, S.; Zhou, Y.; Chen, Y.; Gu, J. Fastp: An ultra-fast all-in-one FASTQ preprocessor. Bioinformatics 2018, 34, i884-i890. [CrossRef] 
79. Langmead, B.; Salzberg, S.L. Fast gapped-read alignment with Bowtie 2. Nat. Methods 2012, 9, 357-359. [CrossRef] [PubMed]

80. Liao, Y.; Smyth, G.K.; Shi, W. FeatureCounts: An efficient general purpose program for assigning sequence reads to genomic features. Bioinformatics 2014, 30, 923-930. [CrossRef] [PubMed]

81. Robinson, M.D.; McCarthy, D.J.; Smyth, G.K. EdgeR: A bioconductor package for differential expression analysis of digital gene expression data. Bioinformatics 2010, 26, 139-140. [CrossRef]

82. Pfaffl, M.W. A new mathematical model for relative quantification in Real-Time RT-PCR. Nucleic Acids Res. 2001, 29 , e45. [CrossRef] [PubMed]

83. Schulz, S.; Häussler, S. Chromatin immunoprecipitation for ChIP-chip and ChIP-seq. In Pseudomonas Methods and Protocols; Filloux, A., Ramos, J.-L., Eds.; Methods in Molecular Biology; Springer: New York, NY, USA, 2014; pp. 591-605. ISBN 978-1-4939-0473-0

84. Kawalek, A.; Bartosik, A.A.; Glabski, K.; Jagura-Burdzy, G. Pseudomonas aeruginosa partitioning protein ParB acts as a nucleoidassociated protein binding to multiple copies of a ParS-related motif. Nucleic Acids Res. 2018, 46, 4592-4606. [CrossRef] [PubMed]

85. Li, H.; Handsaker, B.; Wysoker, A.; Fennell, T.; Ruan, J.; Homer, N.; Marth, G.; Abecasis, G.; Durbin, R. 1000 Genome project data processing subgroup the sequence alignment/map format and SAMtools. Bioinformatics 2009, 25, 2078-2079. [CrossRef]

86. Ramírez, F.; Ryan, D.P.; Grüning, B.; Bhardwaj, V.; Kilpert, F.; Richter, A.S.; Heyne, S.; Dündar, F.; Manke, T. DeepTools2: A next generation web server for deep-sequencing data analysis. Nucleic Acids Res. 2016, 44, W160-W165. [CrossRef] [PubMed]

87. Zhang, Y.; Liu, T.; Meyer, C.A.; Eeckhoute, J.; Johnson, D.S.; Bernstein, B.E.; Nusbaum, C.; Myers, R.M.; Brown, M.; Li, W.; et al. Model-based analysis of ChIP-Seq (MACS). Genome Biol. 2008, 9, R137. [CrossRef]

88. Pettersen, E.F.; Goddard, T.D.; Huang, C.C.; Couch, G.S.; Greenblatt, D.M.; Meng, E.C.; Ferrin, T.E. UCSF Chimera-a visualization system for exploratory research and analysis. J. Comput. Chem. 2004, 25, 1605-1612. [CrossRef]

89. Salamov, V.S.A.; Solovyevand, A. Automatic annotation of microbial genomes and metagenomic sequences. In Metagenomics and Its Applications in Agriculture, Biomedicine and Environmental Studies; Li, R.W., Ed.; Nova Science Publishers: Hauppauge, NY, USA, 2011; pp. 61-78.

90. Goudenège, D.; Avner, S.; Lucchetti-Miganeh, C.; Barloy-Hubler, F. CoBaltDB: Complete bacterial and archaeal orfeomes subcellular localization database and associated resources. BMC Microbiol. 2010, 10, 88. [CrossRef]

91. Simon, R.; O'Connell, M.; Labes, M.; Pühler, A. Plasmid vectors for the genetic analysis and manipulation of rhizobia and other gram-negative bacteria. Methods Enzymol. 1986, 118, 640-659. [PubMed] 